\title{
Thermodynamic Modeling of $\mathrm{CO}_{2}$ Separation Systems with Soluble, Redox-Active Capture Species
}

Lauren E. Clarke, McLain E. Leonard, T. Alan Hatton, and Fikile R. Brushett*

Department of Chemical Engineering, Massachusetts Institute of Technology, Cambridge, Massachusetts 02139, United States

* Corresponding author (F.R. Brushett, brushett@mit.edu) 


\begin{abstract}
Electrochemical approaches hold promise for energy-efficient and modular carbon dioxide $\left(\mathrm{CO}_{2}\right)$ separation systems that can make direct use of renewably-generated electricity. Here we employ a thermodynamic modeling approach to estimate the upper performance bounds of $\mathrm{CO}_{2}$ separation processes that use soluble, redox-active capture species. We contemplate the impact of tunable molecular and electrolyte properties on the thermodynamic and faradaic efficiencies of four characteristic system configurations. We find a tradeoff between these efficiency metrics, and propose a new metric, the combined efficiency, that can be used to further explore this tradeoff and identify desirable property sets that balance energy and materials requirements. Subsequently, we determine effective $\mathrm{CO}_{2}$ binding affinities of redox-active capture molecules and demonstrate how these values are dependent upon molecular properties, system format, and operating conditions. Overall, this analytical framework can help guide molecular discovery and electrolyte engineering in this emerging field by providing insight into target material properties.
\end{abstract}




\section{INTRODUCTION}

Deep society-wide decarbonization to limit global temperature rise to less than $1.5-2^{\circ} \mathrm{C}$ by the turn of the century will require development, manufacture, and deployment of transformative carbon-neutral and carbon-negative technologies on a global scale. Renewable energy sources will be essential in the future low-carbon economy; however, during this transition, the cumulative $\mathrm{CO}_{2}$ emissions may exceed the target threshold due the long technical and economic lifetimes of current fossil-fuel infrastructure and the growing energy demand. ${ }^{1,2}$ Carbon dioxide $\left(\mathrm{CO}_{2}\right)$ capture coupled with storage or utilization can be used to facilitate this transition by reducing emissions of current technologies, addressing hard-to-decarbonize sectors, and even providing a means to reduce cumulative emissions through net-negative applications. ${ }^{1}$ As a result, $\mathrm{CO}_{2}$ capture is projected to play a key role in this global transformation. ${ }^{1,2}$ For large, stationary emissions sources, such as fossil-fuel power plants and industrial processes, the preferred pathway for $\mathrm{CO}_{2}$ removal involves separating $\mathrm{CO}_{2}$ from flue gas in post-combustion capture. ${ }^{3,4}$ For small, stationary (e.g., residential sector) and mobile (i.e., transportation sector) $\mathrm{CO}_{2}$ sources, this strategy is more difficult. Direct air capture (DAC), where $\mathrm{CO}_{2}$ is separated from air, is one method that can be used to account for these emissions. In the long-term, operation of DAC processes could enable the achievement of net-negative $\mathrm{CO}_{2}$ emissions. ${ }^{5}$

Though various $\mathrm{CO}_{2}$ separation strategies exist, the most mature technologies involve thermochemical reactions. These systems rely on enthalpically-driven, chemical absorption (adsorption) reactions at ambient temperatures, followed by an input of heat to overcome the positive reaction enthalpy of the desorption step(s) to recover $\mathrm{CO}_{2}$ and regenerate the liquid solvent (solid sorbent). ${ }^{6-8}$ There are currently several commercialized processes for both post-combustion capture (e.g., KM-CDR Process ${ }^{\mathrm{TM}},{ }^{9}$ Shell Cansolv ${ }^{\circledR} \mathrm{CO}_{2}$ Capture System, ${ }^{10}$ and Econamine FG 
Plus $^{\text {SM }}$ technology ${ }^{11}$ ) and DAC (e.g., Climeworks, ${ }^{12}$ Global Thermostat ${ }^{13}$, and Carbon Engineering ${ }^{14}$ ), which are either under development, in pilot/demonstration scale testing, or operational. However, broad adoption is presently challenged by both technical and economic factors. In general, the efficiencies of thermal separations are constrained by Carnot limitations. ${ }^{15-}$ ${ }^{17}$ Subsequently, these approaches are energy-intensive, specifically during the desorption step. ${ }^{18,19}$ Current post-combustion capture and DAC processes using these chemical absorption (adsorption) methods require ca. $28-43$ and $180-440 \mathrm{~kJ} \mathrm{~mol} \mathrm{CO}_{2}{ }^{-1}$ of thermal energy, respectively. ${ }^{8,20-22}$ In comparison, the minimum energy of separating $\mathrm{CO}_{2}$ from flue gas generated at coal and oil power plants is ca. 6-7 kJ mol CO${ }_{2}^{-1}$, and for DAC it is ca. $20 \mathrm{~kJ} \mathrm{~mol} \mathrm{CO}_{2}^{-1}$, which demonstrates the inefficiency of current processes. Many of the solvent and sorbent materials are also susceptible to thermal and chemical degradation during regeneration, which can lead to performance decay, equipment damage, and operational issues overtime. ${ }^{23,24}$

As an alternative, electrochemical approaches have been proposed, for which electrode potential is the dominant driving force. In these technologies, electrode potentials are modulated to initiate electrochemical reactions that either activate or deactivate the capture medium, enabling $\mathrm{CO}_{2}$ capture or release. As compared to thermochemical processes, electrochemical technologies provide a pathway for operating at higher efficiencies due to their direct conversion of electrical energy into chemical energy, thereby circumventing Carnot limitations. ${ }^{25}$ Electrochemicallydriven processes have other benefits as well — they are modular and, thus, scalable across various process sizes, can be operated at milder conditions, and can directly utilize low-carbon electrical power. $^{26,27}$

Approaches to electrochemical $\mathrm{CO}_{2}$ separation, in general, include either direct or indirect modulation of the $\mathrm{CO}_{2}$-binding affinity of the capture medium. Indirect approaches utilize faradaic 
reactions to alter the electrolyte environment and thereby influence the binding capabilities of a capture molecule (which does not undergo electrochemical transformations itself). Electrochemically-mediated amine regeneration (EMAR) is one indirect approach which makes use of the same absorption step as amine-based solvent systems for post-combustion capture. However, the regeneration step is carried out electrochemically rather than thermochemically. Specifically, copper cations $\left(\mathrm{Cu}^{2+}\right)$ are introduced into the solution via oxidation of a copper $(\mathrm{Cu})$ anode. The amine molecules preferentially bind $\mathrm{Cu}^{2+}$ in the electrolyte solution, releasing $\mathrm{CO}_{2}$. The amine solvent and copper are then regenerated via a reduction step, in which $\mathrm{Cu}$ is electrodeposited onto a cathode. ${ }^{28,29}$ Although still in development, this electrochemical approach is currently projected to have energy requirements of ca. $50-60 \mathrm{~kJ}$ mol $\mathrm{CO}_{2}^{-1}$ (including $\mathrm{CO}_{2}$ compression) which is similar to state-of-the-art post-combustion capture, while also having the ability to avoid high-temperature amine degradation. ${ }^{30}$ Another indirect approach leverages proton-coupled electron transfer reactions to generate a $\mathrm{pH}$ gradient across an electrochemical cell, facilitating the capture of $\mathrm{CO}_{2}$ in the form of bicarbonate/carbonate on the high-pH side and release on the low-pH side. ${ }^{31-37}$ Estimates of the minimum energy consumption for a $\mathrm{pH}$-swing $\mathrm{CO}_{2}$ capture process are similar to that of the EMAR process $\left(60 \mathrm{~kJ} \mathrm{~mol} \mathrm{CO}_{2}{ }^{-1}\right) .{ }^{34}$

Direct approaches for electrochemical $\mathrm{CO}_{2}$ separation involve the use of redox-active, $\mathrm{CO}_{2}$ capture molecules. The overall process can be characterized by four reactions, as outlined in Equations $1-4$, where $\mathrm{R}$ represents a generic capture molecule.

$$
\begin{aligned}
& \mathrm{R}+n \mathrm{e}^{-} \leftrightarrow \mathrm{R}^{n-} \\
& \mathrm{R}^{n-}+q \mathrm{CO}_{2} \stackrel{K_{1}}{\leftrightarrow} \mathrm{R}\left(\mathrm{CO}_{2}\right)_{q}^{n-} \\
& \mathrm{R}\left(\mathrm{CO}_{2}\right)_{q}+n \mathrm{e}^{-} \leftrightarrow \mathrm{R}\left(\mathrm{CO}_{2}\right)_{q}^{n-} \\
& \mathrm{R}+q \mathrm{CO}_{2} \stackrel{K_{2}}{\leftrightarrow} \mathrm{R}\left(\mathrm{CO}_{2}\right)_{q}
\end{aligned}
$$


In this process, capture species (R) can either be dissolved in an electrolyte ${ }^{38-47}$ or immobilized on an electrode surface. ${ }^{48,49}$ The $\mathrm{R}$ molecules are activated via electroreduction $\left(\mathrm{R}^{n-}\right)$ to increase their nucleophilicity and, thus, $\mathrm{CO}_{2}$-binding affinity $\left(K_{1}\right)$. Following an absorption step, the $\mathrm{CO}_{2}-$ bound molecules $\left(\mathrm{R}\left(\mathrm{CO}_{2}\right)_{q}^{n-}\right)$ are electrooxidized $\left(\mathrm{R}\left(\mathrm{CO}_{2}\right)_{q}\right)$, reducing their binding affinity $\left(K_{2}\right)$ and facilitating the release of $\mathrm{CO}_{2} \cdot{ }^{38}$ Several molecular families have been shown to be capable of capturing and releasing $\mathrm{CO}_{2}$ in this manner including quinones, ${ }^{38-42,48-50}$ bipyridines, ${ }^{43,44}$ thiolates, ${ }^{45}$ and transition metal complexes. ${ }^{46,47}$ Aromatic molecules and coordination complexes, as such, are broadly attractive because key physical and electrochemical properties can be tuned through synthetic design to achieve targeted molecular properties. The ability to optimize the properties of these capture species can enable higher efficiency separations. Many of these molecular families, such as quinones, are also composed of relatively cheap and abundant starting materials. $^{51}$

Proper design of redox-active capture media is essential to the development of systems with competitive energetic and capture efficiencies, necessitating the identification of suitable redox molecules and electrolyte formulations. However, the breadth and diversity of the potential chemical design space challenges experimental research efforts, especially if desired property profiles are not well-defined or not readily achievable with present materials. To this end, modeling can aid in understanding how specific design variables impact performance and can offer insight into favorable combinations of material sets, device formats, and operating conditions. In particular, thermodynamic modeling, the focus of this study, can serve as a computationally concise approach to quantifying the upper limits on system performance and assessing how those limits are impacted by molecule/electrolytes pairs, system configurations, and operating strategies. In previous work, Shaw and Hatton detailed a framework for electrochemical $\mathrm{CO}_{2}$ separations 
which can be used to evaluate the thermodynamic limit on energy requirements $\left(\mathrm{kJ} \mathrm{mol} \mathrm{CO}_{2}^{-1}\right)$ of four different system configurations. ${ }^{52}$ They demonstrated that choice of configuration impacts both system energetics and how these energy requirements are affected by certain molecular properties (e.g., binding affinity and $\mathrm{CO}_{2}$ solubility). This framework, or a similar approach, has been applied to assess the energetic limits for $\mathrm{EMAR}^{28-30}$ and $\mathrm{pH}$-swing ${ }^{33,34}$ systems. In these works, Wang et al. ${ }^{30}$ and Rahimi et al. ${ }^{33}$ evaluated energetic limits for specific electrolyte compositions and chemistries used in EMAR and pH-swing technologies, respectively. Comparatively, Stern et al. began to assess the impact of binding strength on EMAR systems, which is a chemistry-dependent characteristic. ${ }^{28,29}$ For direct approaches with soluble, redox-active sorbents, DuBois et al..$^{38}$ and Scovazzo et al. ${ }^{41}$ used thermodynamic relations to investigate binding coefficient requirements $\left(K_{1}\right.$ and $\left.K_{2}\right)$ for separating $\mathrm{CO}_{2}$ at a given capture species concentration, and how this may be impacted by $\mathrm{CO}_{2}$ solubility.

Here, building upon these prior works, we perform a more comprehensive thermodynamic analysis of electrochemical separation systems which use soluble, redox-active capture molecules to directly capture and release $\mathrm{CO}_{2}$. Rather than focusing on a specific electrolyte composition and chemistry, we vary associated molecular properties to assess how these design factors impact performance limits. We describe a thermodynamic modeling framework (Sections 2.1-2.3) to assess the thermodynamic (energetic) and faradaic efficiencies (Sections 3.1 and 3.2) of these electrochemical $\mathrm{CO}_{2}$ separation systems. We specifically investigate the impact of molecular properties on these efficiencies for different system configurations using a model post-combustion capture case. We observe competing trends between the thermodynamic and faradaic efficiencies and define a new metric, the combined efficiency, to explore this tradeoff and understand the impact of molecular properties, operating factors, and system configurations (Section 3.3). Using 
the combined efficiency, we highlight properties of capture molecule and electrolyte pairs that may be effective in adequately balancing this inherent tradeoff, and which system configurations and process applications (post-combustion capture vs. DAC) these pairs may be most successful in (Sections 3.4 and 3.5).

To this end, findings from this work can guide aspects of on-going molecular discovery and electrolyte engineering efforts. While we specifically analyze direct electrochemical $\mathrm{CO}_{2}$ separation methods which use solubilized sorbents, this framework can be adapted and extended to other approaches (e.g. EMAR or pH-swings), as well as to immobilized (i.e. non-solubilized) capture species. ${ }^{52}$ Overall, this thermodynamic model and associated analysis can support and potentially accelerate molecular discovery, system development, and ultimately deployment of electrochemical $\mathrm{CO}_{2}$ separation technologies.

\section{THERMODYNAMIC MODEL}

In this section, we outline the key equations in this thermodynamic modeling approach and highlight underlying assumptions. This approach considers four lumped reactions, as shown in Equations 1-4, which include the binding or release of $q \mathrm{CO}_{2}$ molecules and the transfer of $n$ electrons in a concerted fashion. It is assumed that a state of chemical and electrochemical equilibrium exists throughout the separation cycle according to these four reactions. The vapor and liquid phases are also assumed to behave as an ideal gas and ideal solution, respectively. Accordingly, the species activity coefficients are unity and the dissolved concentration of $\mathrm{CO}_{2}$ can be related to its partial pressure via Henry's law, $\left[\mathrm{CO}_{2}\right]=\mathrm{H}_{\mathrm{CO}_{2}} P_{\mathrm{CO}_{2}}$. In this expression, $\left[\mathrm{CO}_{2}\right]$ is the concentration of $\mathrm{CO}_{2}$ dissolved in the electrolyte (mol L-1), $\mathrm{H}_{\mathrm{CO}_{2}}$ is the Henry's law constant for $\mathrm{CO}_{2}\left(\mathrm{~mol} \mathrm{~L}-1\right.$ bar $\left.{ }^{-1}\right)$, and $P_{\mathrm{CO}_{2}}$ is the $\mathrm{CO}_{2}$ partial pressure (bar). Finally, it is assumed that the system operates isothermally and all gas streams enter and exit the process at atmospheric 
conditions (298.15 K and $1 \mathrm{bar})$. A more rigorous thermodynamic modeling approach has been demonstrated for EMAR and $\mathrm{pH}$-swing processes, which incorporate various speciation reactions and solution non-idealities via activity coefficient models. ${ }^{30,33}$ In comparison, here we applied these simplifying assumptions, as described, to focus on general, thermodynamic trends of these systems without considering specific electrolyte chemistries. All other assumptions will be stated throughout this section and detailed further in the Supporting Information (SI) if necessary.

In this approach, we solve for concentration and electrochemical potential variation simultaneously at each electrode as the capture species is activated (cathode) and deactivated (anode). Determination of the electrode potentials and $\mathrm{CO}_{2}$ concentrations enable estimation of energy requirements for the capture and release of $\mathrm{CO}_{2}$ on a molar basis. This permits the computation of a thermodynamic efficiency by comparing the calculated energy requirements to the minimum energy of $\mathrm{CO}_{2}$ separation. We also compute the number of moles of $\mathrm{CO}_{2}$ captured and released per mole of electron that is transferred as a measure of faradaic efficiency.

\subsection{Governing Equations}

The electrochemical potential for each redox reaction is modeled using the Nernst equation. For the reactions shown in Equations 1 and 3, the electrode potentials are represented by Equations 5 and 6, respectively:

$$
\begin{aligned}
& E=E_{1,0}-\frac{R_{\mathrm{u}} T}{n F} \cdot \ln \left(\frac{\left[\mathrm{R}^{n-}\right]}{[\mathrm{R}]}\right) \\
& E=E_{2,0}-\frac{R_{\mathrm{u}} T}{n F} \cdot \ln \left(\frac{\left[\mathrm{R}\left(\mathrm{CO}_{2}\right)_{-}^{n-}\right]}{\left[\mathrm{R}\left(\mathrm{CO}_{2}\right)_{q}\right]}\right)
\end{aligned}
$$

where $E$ is the electrode potential $(\mathrm{V}), E_{1,0}$ represents the standard reduction potential of the R/R ${ }^{n-}$ redox couple, $E_{2,0}$ represents the standard reduction potential of the $\mathrm{R}\left(\mathrm{CO}_{2}\right)_{q} / \mathrm{R}\left(\mathrm{CO}_{2}\right)_{q}^{n-}$ redox couple, $R_{u}$ is the universal gas constant $\left(8.314 \mathrm{~J} \mathrm{~mol}^{-1} \mathrm{~K}^{-1}\right), T$ is the absolute temperature $(\mathrm{K})$, and $F$ is the Faraday constant $\left(96485 \mathrm{C} \mathrm{mol}^{-1}\right)$. For an ideal solution, the activity of each ionic species 
is determined as its concentration divided by the standard state for ions in an ideal solution (1 molal solution). As an approximation, molar concentrations can be used as a substitute for molalities, and the standard concentration, $\left[\mathrm{C}_{0}\right]$, is $1 \mathrm{~mol} \mathrm{~L}^{-1}{ }^{8}$ In the Nernstian expression for the reactions considered in this system, the standard concentrations cancel resulting in Equations 5 and 6.

The total capture species concentration, $\left[\mathrm{R}_{0}\right]\left(\mathrm{mol} \mathrm{L}^{-1}\right)$, is equivalent to the total concentration of the capture species in all four states, as shown in Equation 7.

$$
\left[\mathrm{R}_{0}\right]=\left[\mathrm{R}^{n-}\right]+\left[\mathrm{R}\left(\mathrm{CO}_{2}\right)_{q}^{n-}\right]+[\mathrm{R}]+\left[\mathrm{R}\left(\mathrm{CO}_{2}\right)_{q}\right]
$$

It is assumed that this concentration remains constant. This is used as a basis of normalization for the capture species concentrations. Equation 8 shows that the electrolyte state of charge, $x_{\mathrm{a}}(-)$, is defined by the total, dimensionless concentration of the capture species in its reduced states.

$$
x_{\mathrm{a}}=\frac{\left[\mathrm{R}^{n-}\right]+\left[\mathrm{R}\left(\mathrm{CO}_{2}\right)_{q}^{n-}\right]}{\left[\mathrm{R}_{0}\right]}
$$

The range of $x_{\mathrm{a}}$ is 0 to 1 due to normalization by $\left[\mathrm{R}_{0}\right]$. The state of charge swing, $\Delta x_{\mathrm{a}}$, is defined as the change in state of charge during cathodic reduction and anodic oxidation. It is assumed that the system operates symmetrically around $x_{\mathrm{a}}=0.5$. This means that the initial and final states of charge during the reduction step are $0.5-\frac{\Delta x_{\mathrm{a}}}{2}$ and $0.5+\frac{\Delta x_{\mathrm{a}}}{2}$, respectively, and the opposite is true for the oxidation step.

This framework also incorporates three dimensionless parameter groupings, which reduces the number of independent variables considered. The binding coefficients for dissolved $\mathrm{CO}_{2}, K_{1}$ and $K_{2}$, can be grouped with the Henry's law constant for $\mathrm{CO}_{2}, \mathrm{H}_{\mathrm{CO}_{2}}$, as such:

$$
\begin{aligned}
& K_{\mathrm{g}, 1}=\frac{\left[\mathrm{R}\left(\mathrm{CO}_{2}\right)_{q}^{n-}\right]}{\left[\mathrm{R}^{n-}\right]\left(\tilde{P}_{\mathrm{CO}_{2}}\right)^{q}}=\left(H_{\mathrm{CO}_{2}} \frac{P_{0}}{\left[\mathrm{C}_{0}\right]}\right)^{q} K_{1} \\
& K_{\mathrm{g}, 2}=\frac{\left[\mathrm{R}\left(\mathrm{CO}_{2}\right)_{q}\right]}{[\mathrm{R}]\left(\tilde{P}_{\mathrm{CO}_{2}}\right)^{q}}=\left(H_{\mathrm{CO}_{2}} \frac{P_{0}}{\left[\mathrm{C}_{0}\right]}\right)^{q} K_{2}
\end{aligned}
$$


where $\tilde{P}_{\mathrm{CO}_{2}}$ is the dimensionless $\mathrm{CO}_{2}$ partial pressure, $\tilde{P}_{\mathrm{CO}_{2}}=P_{\mathrm{CO}_{2}} / P_{0}$, with $P_{0}$ as the standard pressure of 1 bar. Similar to the derivation of the Nernst expressions in Equations 5 and 6, the standard concentrations of the capture species cancel due to equivalent stoichiometric coefficients in the reaction expressions. Physically, these groupings, $K_{\mathrm{g}, 1}$ and $K_{\mathrm{g}, 2}$, represent binding coefficients relative to gaseous $\mathrm{CO}_{2}\left(K_{\mathrm{g}, 1}\right.$ and $\left.K_{\mathrm{g}, 2}\right)$. Furthermore, $K_{\mathrm{g}, 1}$ and $K_{\mathrm{g}, 2}$ are properties that can be measured or readily computed from $K_{1}$ and $K_{2}$ if $\mathrm{CO}_{2}$ solubility in a given electrolyte is known.

The third dimensionless grouping is defined here as the relative $\mathrm{CO}_{2}$ solubility, $\widetilde{H}_{\mathrm{CO}_{2}}$, which is shown in Equation 11.

$$
\widetilde{H}_{\mathrm{CO}_{2}}=\frac{H_{\mathrm{CO}_{2}} P_{0}}{q\left[\mathrm{R}_{0}\right]}
$$

This variable represents the $\mathrm{CO}_{2}$ solubility at standard pressure $(1$ bar $)$ relative to the maximum quantity of $\mathrm{CO}_{2}$ that can be bound by a capture species at concentration $\left[\mathrm{R}_{0}\right]$.

Equating the potential expressions in Equations 5 and 6 and incorporating the binding coefficients from Equations 9 and 10 shows that the difference between the standard reduction potentials, $E_{2,0}$ and $E_{1,0}$, can be described directly by the ratio of binding coefficients, $K_{\mathrm{g}, 1}$ and $K_{\mathrm{g}, 2}$, in Equation $12 .^{53}$

$$
E_{2,0}-E_{1,0}=\frac{R_{\mathrm{u}} T}{n F} \ln \left(\frac{K_{\mathrm{g}, 1}}{K_{\mathrm{g}, 2}}\right)
$$

Using Equations 7-10, the electrode potential can be expressed in terms of $x_{\mathrm{a}}, K_{\mathrm{g}, 1}, K_{\mathrm{g}, 2}, \widetilde{P}_{\mathrm{CO}_{2}}$, $n$, and $q$, either starting from Equation 5 or the combination of Equations 6 and 12. We represent the potential as a deviation, as described in Equation 13.

$$
E_{\mathrm{dev}}=\frac{R_{\mathrm{u}} T}{n F}\left[\ln \left(\frac{1-x_{\mathrm{a}}}{x_{\mathrm{a}}}\right)+\ln \left(\frac{1+K_{\mathrm{g}, 1}\left(\tilde{P}_{\mathrm{CO}_{2}}\right)^{q}}{1+K_{\mathrm{g}, 2}\left(\tilde{P}_{\mathrm{CO}_{2}}\right)^{q}}\right)\right]
$$


Here, $E_{\mathrm{dev}}$ is the deviation potential $(\mathrm{V})$, representing the difference between the electrode potential and the $\mathrm{R} / \mathrm{R}^{n-}$ standard reduction potential, $E-E_{1,0}$. In this framework, the specific value of $E_{1,0}$ is unimportant. As described in Section 2.3 (vide infra), the energy requirements are computed from the difference between the electrode potentials which is equivalent to the difference between their deviation potentials. Overall, Equation 13 allows for evaluation of both the anode and cathode deviation potentials as a function of the state of charge $\left(x_{\mathrm{a}}\right)$ and $\mathrm{CO}_{2}$ partial pressure $\left(\tilde{P}_{\mathrm{CO}_{2}}\right)$ as the capture species is activated/deactivated. Throughout this work, we will refer to the electrode potential deviation as the electrode potential when describing the impact of certain parameters on $E^{\mathrm{dev}}$, for purpose of brevity. The complete derivation for Equation 13 can be found in Section S.2.1 of the SI.

The state of charge and $\mathrm{CO}_{2}$ partial pressure may vary concurrently due to both chemical and physical absorption of $\mathrm{CO}_{2}$ into and out of solution driven by reactions of the redox-active capture molecule. $\mathrm{A} \mathrm{CO}_{2}$ mole balance expression is also included to describe the total concentration of $\mathrm{CO}_{2}$ in the liquid electrolyte, $\left[\mathrm{CO}_{2}\right]_{\mathrm{T}}$, which is comprised of dissolved $\mathrm{CO}_{2}\left(\left[\mathrm{CO}_{2}\right]\right)$ and $\mathrm{CO}_{2}$ bound to the capture species $\left(\left[\mathrm{R}\left(\mathrm{CO}_{2}\right)_{q}\right]\right.$ and $\left.\left[\mathrm{R}\left(\mathrm{CO}_{2}\right)_{q}^{n-}\right]\right)$. The total concentration of $\mathrm{CO}_{2}$ can be normalized by $q\left[\mathrm{R}_{0}\right]$, which is represented by the variable $x_{\mathrm{CO}_{2}}$, yielding the following expression in Equation 14.

$$
x_{\mathrm{CO}_{2}}=\frac{\left[\mathrm{CO}_{2}\right]_{\mathrm{T}}}{q\left[\mathrm{R}_{0}\right]}=\frac{q\left[\mathrm{R}\left(\mathrm{CO}_{2}\right)_{q}\right]}{q\left[\mathrm{R}_{0}\right]}+\frac{q\left[\mathrm{R}\left(\mathrm{CO}_{2}\right)_{q}^{n-}\right]}{q\left[\mathrm{R}_{0}\right]}+\frac{\left[\mathrm{CO}_{2}\right]}{q\left[\mathrm{R}_{0}\right]}
$$

Normalization of $\left[\mathrm{CO}_{2}\right]_{\mathrm{T}}$ by $q\left[\mathrm{R}_{0}\right]$ means that this variable can exceed a value of 1 due to the presence of dissolved $\mathrm{CO}_{2}$. Equation 14 can also be represented in terms of $x_{\mathrm{a}}, K_{\mathrm{g}, 1}, K_{\mathrm{g}, 2}, \tilde{P}_{\mathrm{CO}_{2}}$, and q, which is presented in Equation 15.

$$
x_{\mathrm{CO}_{2}}=\left(1-x_{\mathrm{a}}\right)\left(\frac{K_{\mathrm{g}, 2}\left(\tilde{P}_{\mathrm{CO}_{2}}\right)^{q}}{1+K_{\mathrm{g}, 2}\left(\tilde{P}_{\mathrm{CO}_{2}}\right)^{q}}\right)+x_{\mathrm{a}}\left(\frac{K_{\mathrm{g}, 1}\left(\tilde{P}_{\mathrm{CO}_{2}}\right)^{q}}{1+K_{\mathrm{g}, 1}\left(\tilde{P}_{\mathrm{CO}_{2}}\right)^{q}}\right)+\widetilde{H}_{\mathrm{CO}_{2}} \tilde{P}_{\mathrm{CO}_{2}}
$$


The complete derivation of Equation 15 can be found in Section S.2.2. In this framework, Equation 15 is coupled with the Nernstian expression in Equation 13 as described in Section 2.3 (vide infra).

\subsection{System Configurations}

Thermodynamic calculations using this framework are also impacted by aspects of system design. Four system configurations have been identified for electrochemical $\mathrm{CO}_{2}$ separations, which each follow a different thermodynamic path. ${ }^{52}$ Examples of these configurations are illustrated in Figure 1 for a direct approach using soluble, redox-active capture molecules. In a 4stage system, an electrolytic cell is used for activation and deactivation of the capture species, whereas the $\mathrm{CO}_{2}$ absorption and desorption steps primarily occur in separate process units. Incorporation of a cathode that allows for 3-phase contact (e.g., gas-diffusion electrode) enables simultaneous activation of the capture species and $\mathrm{CO}_{2}$ absorption, which can be termed cathodic absorption. With cathodic absorption, a 3-stage system is adopted. Similarly, a 3-stage system can be adopted with simultaneous capture species deactivation, $\mathrm{CO}_{2}$ desorption, and $\mathrm{CO}_{2}$ removal from the anode, which can be termed anodic desorption. If cathodic absorption and anodic desorption can both occur within the electrochemical cell, the process is considered a 2-stage system. 
(a)
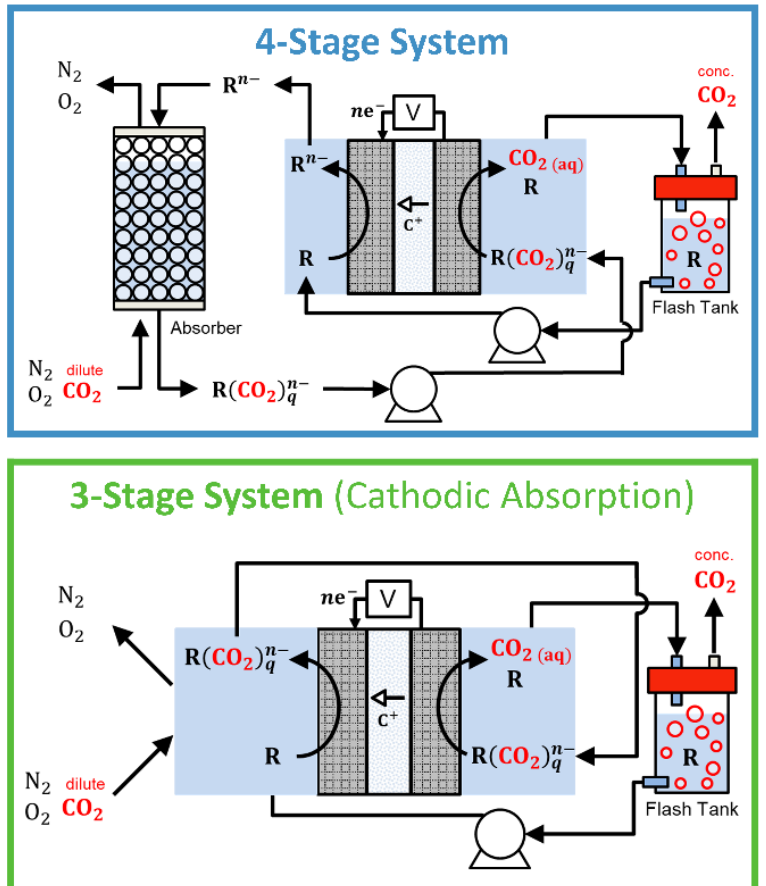

(c) (b)
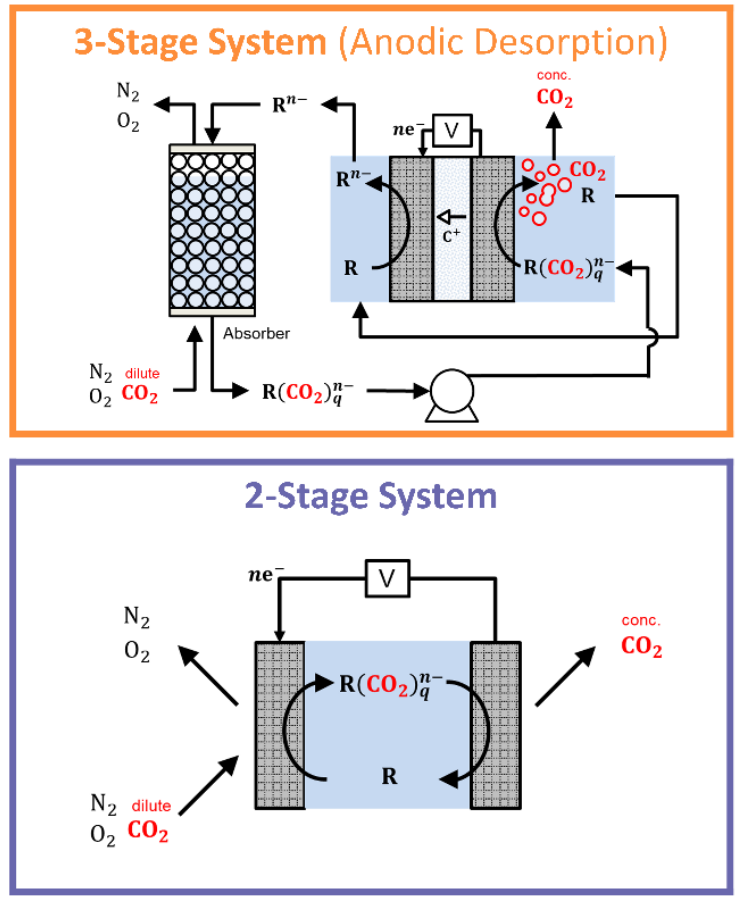

(d)

Figure 1. Demonstrations of the four system configurations for electrochemical $\mathrm{CO}_{2}$ separations for direct methods with soluble, redox-active capture molecules: (a) 4-stage system, (b) 3-stage system with anodic desorption, (c) 3-stage system with cathodic absorption, and (d) 2-stage system with both cathodic absorption and anodic desorption. In these schematics, the $\mathrm{C}^{+}$with an arrow represents the transport of positively charged cations to maintain a balance of charge.

An exemplar thermodynamic path for a 4-stage system is shown in Figure 2, demonstrating how cathode and anode potentials vary as functions of the state of charge. Specifically, points 1 and 2 represent the cathode initial and final state of charge, respectively, and points 3 and 4 represent the anode initial and final state of charge, respectively. For the 4-stage system, no $\mathrm{CO}_{2}$ is introduced to or removed from the electrodes, thus $x_{\mathrm{CO}_{2}}$ remains constant during electrochemical steps. At each point, two of three variables $\left(x_{\mathrm{CO}_{2}}, x_{\mathrm{a}}\right.$, and $\left.\tilde{P}_{\mathrm{CO}_{2}}\right)$ are known, and Equation 15 is used to determine the unknown third. Equation 15 can also be used to solve for $\widetilde{P}_{\mathrm{CO}_{2}}$ at each value along the electrode state of charge path, such that the electrode potential curve can be generated using 
Equation 13. An important assumption made here for system configurations which lack cathodic absorption, as does a 4-stage system, is that the absorption step is performed in a countercurrent flow unit (as shown in Figure 1(a)). This is a typical case for gas-liquid absorption units in $\mathrm{CO}_{2}$ capture processes. ${ }^{54}$ Given this assumption, the $\mathrm{CO}_{2}$-rich feed gas entering the absorber is in equilibrium with the $\mathrm{CO}_{2}$-saturated electrolyte exiting the unit, and the $\mathrm{CO}_{2}$-depleted raffinate stream is in equilibrium with the activated electrolyte entering the absorber. Due to this assumption, the $\mathrm{CO}_{2}$ partial pressure of the electrolyte following absorption and prior to anodic oxidation is equal to that of the feed gas, $\tilde{\mathrm{PO}}_{\mathrm{CO}_{2}, 3}=\tilde{P}_{\mathrm{CO}_{2} \text {,feed }}$. Additionally, the partial pressure of the gaseous raffinate stream will be equal to that of the electrolyte following cathodic reduction, $\tilde{P}_{\mathrm{CO}_{2} \text {,raf }}=\tilde{P}_{\mathrm{CO}_{2}, 2}$. Detailed descriptions of how all four configurations are analyzed can be found in the Section S.3 of the SI. For systems with cathodic absorption, an additional mole balance expression is required which is described in Section S.3.2. 


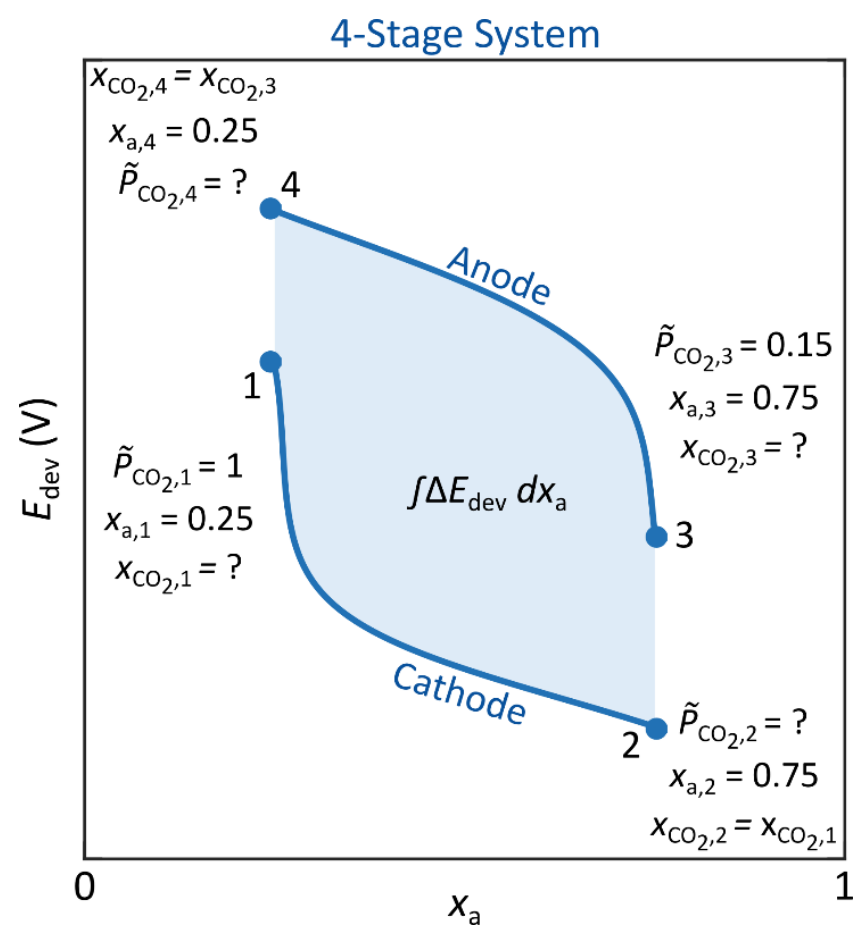

Figure 2. A qualitative demonstration of electrode potentials as a function of state of charge $\left(x_{\mathrm{a}}\right)$ for a 4-stage system implemented for a post-combustion capture process $\left(\tilde{P}_{\mathrm{CO}_{2}, \text { feed }}=0.15\right)$. For this configuration, points 1 and 2 represent the cathode initial and final $x_{\mathrm{a}}$, and points 3 and 4 represent the anode initial and final $x_{\mathrm{a}}$. For a 4-stage system, no $\mathrm{CO}_{2}$ is introduced or removed during the electrochemical transformations at the electrodes, and therefore activation/deactivation of the capture species follows a constant $x_{\mathrm{CO}_{2}}$ path. For this demonstration, a state of charge swing $\left(\Delta x_{\mathrm{a}}\right)$ of 0.5 was assumed.

\subsection{Energetics and System Efficiencies}

The work required to separate 1 mole of $\mathrm{CO}_{2}, W\left(\mathrm{~J} \mathrm{~mol} \mathrm{CO}_{2}^{-1}\right)$ can be expressed as:

$$
W=\frac{n F \int \Delta E_{\mathrm{dev}} d x_{\mathrm{a}}}{q \Delta x_{\mathrm{CO}_{2}}}
$$

where $\Delta E_{\mathrm{dev}}(\mathrm{V})$ is the difference between the cathode and anode potentials and $\Delta x_{\mathrm{CO}_{2}}$ is the difference between the normalized total $\mathrm{CO}_{2}$ concentration following absorption $\left(x_{\mathrm{CO}_{2}, 3}\right)$ and desorption $\left(x_{\mathrm{CO}_{2}, 1}\right)$. The calculated work using this thermodynamic framework can be compared to the minimum work of separation, $W_{\min }\left(\mathrm{J} \mathrm{mol} \mathrm{CO}_{2}^{-1}\right)$, which is determined from the free energy difference between process inlet $\left(\mathrm{CO}_{2}\right.$-rich feed gas $)$ and outlet streams $\left(\mathrm{CO}_{2}\right.$ product and $\mathrm{CO}_{2}$ - 
depleted raffinate stream). The expression for $W_{\min }$ of an ideal gas mixture is shown in Equation $17 .^{7}$

$$
\begin{gathered}
W_{\text {min }}=-R_{\mathrm{u}} T\left(\ln \left(\tilde{P}_{\mathrm{CO}_{2}, \text { feed }}\right)+\left(1-\tilde{P}_{\mathrm{CO}_{2}, \text { feed }}\right)\left(\frac{\tilde{P}_{\mathrm{CO}_{2}, \text { raf }}}{\tilde{P}_{\mathrm{CO}_{2}, \text { feed }}-\tilde{P}_{\mathrm{CO}_{2}, \text { raf }}}\right) \ln \left(\frac{\tilde{P}_{\mathrm{CO}_{2}, \text { feed }}}{\tilde{P}_{\mathrm{CO}_{2}, \text { raf }}}\right)+(1-\right. \\
\left.\left.\tilde{P}_{\mathrm{CO}_{2}, \text { feed }}\right)\left(1-\tilde{P}_{\mathrm{CO}_{2}, \text { raf }}\right)\left(\frac{1}{\tilde{P}_{\mathrm{CO}_{2}, \text { feed }}-\tilde{P}_{\mathrm{CO}_{2}, \text { raf }}}\right) \ln \left(\frac{1-\tilde{P}_{\mathrm{CO}_{2}, \text { feed }}}{1-\tilde{P}_{\mathrm{CO}_{2}, \text { raf }}}\right)\right)
\end{gathered}
$$

This $W_{\min }$ value represents the energy requirements of a completely reversible, $\mathrm{CO}_{2}$ separation system. This calculation can also account for partial separation, where a fraction of $\mathrm{CO}_{2}$ is removed from the feed gas. The $\mathrm{CO}_{2}$ capture fraction, $\alpha$, is related to $\widetilde{P}_{\mathrm{CO}_{2} \text {,feed }}$ and $\tilde{P}_{\mathrm{CO}_{2} \text {,raf }}$ according to Equation $18 .^{7}$

$$
\alpha=\left(\frac{\tilde{P}_{\mathrm{CO}_{2}, \text { feed }}-\tilde{P}_{\mathrm{CO}_{2}, \text { raf }}}{\tilde{P}_{\mathrm{CO}_{2}, \text { feed }}}\right)\left(\frac{1}{1-\tilde{P}_{\mathrm{CO}_{2}, \text { raf }}}\right)
$$

We convert energy requirements to an efficiency metric by comparing the work for separation predicted with this thermodynamic framework, $W$, to the minimum work, $W_{\text {min }}$. We define this as the thermodynamic efficiency ( $\left.\eta_{\text {thermodynamic }}\right)$, as presented in Equation 19.

$$
\eta_{\text {thermodynamic }}=\frac{W_{\text {min }}}{W}
$$

This thermodynamic bound serves as the maximum energetic efficiency of this system, prior to accounting for losses due to reaction kinetics, ohmics, mass transport, and other sources of inefficiency.

We add to this existing framework by considering the faradaic efficiency, which is defined here as the moles of $\mathrm{CO}_{2}$ separated per mole of electron transferred, normalized to the ratio of $q / n$ such that it can be defined on a scale of 0 to 1 (or 0 to $100 \%$ ). The faradaic efficiency $\left(\eta_{\text {faradaic }}\right)$ can be determined using Equation 20.

$$
\eta_{\text {faradaic }}=\frac{\Delta x_{\mathrm{CO}_{2}}}{\Delta x_{\mathrm{a}}}
$$


The faradaic efficiency is a measure of the materials utilization efficiency, as it will impact the total quantity of capture material required to separate a given quantity of $\mathrm{CO}_{2}$. This faradaic efficiency represents a maximum achievable value, as the efficiency of any practical embodiment is likely to be lowered by a combination of side reactions, $\mathrm{CO}_{2}$ crossover, and other losses.

Overall, this modeling framework provides a means of assessing the maximum possible thermodynamic and faradaic efficiencies for the electrochemical $\mathrm{CO}_{2}$ separation configurations that are considered. It can be used to posit upper performance bounds and to explore tradeoffs between different thermodynamic metrics. In this study, we apply this framework to evaluate direct systems which use soluble, redox-active capture species.

\section{RESULTS \& DISCUSSION}

Both molecular and system properties will impact $\mathrm{CO}_{2}$ separation performance. Here, we investigate the effect of system configuration, binding coefficients, and relative $\mathrm{CO}_{2}$ solubility on the thermodynamic and faradaic efficiencies. We identify a tradeoff between these two efficiencies, and define a new metric (the combined efficiency) that can be used to further explore this tradeoff and predict molecular properties that may be successful in these systems. Using this new metric, we propose effective values of the binding coefficient, $K_{\mathrm{g}, 1}$, and examine how this is impacted by factors such as the state of charge swing, process application (post-combustion vs. direct air capture), and other parameters.

\subsection{The Impact of System Configuration on Electrode Potentials}

For illustration, Figure 3 qualitatively describes the impact of incorporating cathodic absorption and/or anodic desorption. The outermost (blue) potential curves represent those of a 4-stage system, which lacks both cathodic absorption and anodic desorption. In this system, although the $\mathrm{CO}_{2}$ feed stream is not introduced to the cathode, some $\mathrm{CO}_{2}$ will likely be present due to its finite 
physical solubility in the solvent. As the capture species is activated ( $R$ reduced to $R^{n-}$ ), the equilibrium of the absorption reaction shifts (Equation 2), and therefore dissolved $\mathrm{CO}_{2}$ binds to $\mathrm{R}^{n-}$. However, when cathodic absorption is implemented, the binding reaction equilibrium significantly favors the formation of $\mathrm{R}\left(\mathrm{CO}_{2}\right)_{q}^{n-}$ due to the relative abundance of $\mathrm{CO}_{2}$ near the electrode, which is in line with LeChatlier's principle. The binding reaction acts as a sink for the electrochemical product, $\mathrm{R}^{n-}$, shifting the cathode potential more positive according to the Nernst equation (demonstrated with upward oriented green arrows). Similarly, the desorption reaction occurs at the anode during a 4-stage system according to Equation 4; however, removal of the $\mathrm{CO}_{2}$ product in anodic desorption significantly shifts the equilibrium of this reaction. Again, this reaction removes the electrochemical product, $\mathrm{R}\left(\mathrm{CO}_{2}\right)_{q}$, which shifts the anode potential more negative (demonstrated with orange downward oriented arrows). Thus, incorporation of cathodic absorption and/or anodic desorption decreases the energy requirements of the overall separation process. These trends are in agreement with prior work by Shaw and Hatton. ${ }^{52}$ 


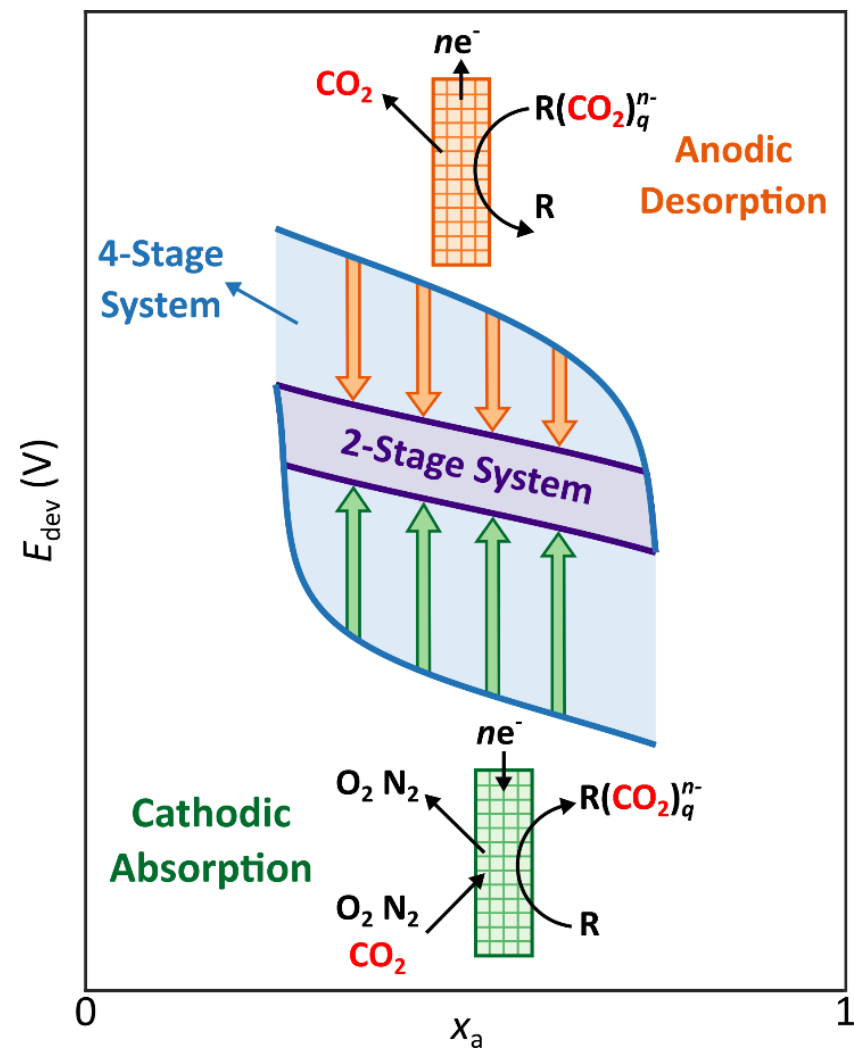

Figure 3. A qualitative comparison of the potential curves and area between the curves for a 4stage (blue, outermost curves) and 2-stage (purple, innermost curves) system. By incorporating cathodic absorption, which is achieved by feeding the $\mathrm{CO}_{2}$-containing feed gas directly to the cathode, the potential curve of the cathode becomes more positive as compared to the 4-stage system (this shift shown by the bottom, green arrows). Similarly, by incorporating anodic desorption where $\mathrm{CO}_{2}$ is removed from the anode, the anodic potential curve is shifted more negative compared to that of the 4-stage system (this shift is shown by the top, orange arrows). The 2-stage system incorporates both cathodic absorption and anodic desorption.

\subsection{The Impacts of Binding Affinity and Relative $\mathrm{CO}_{2}$ Solubility on Efficiencies}

To begin exploring the relationships between molecular properties and process energetics, we first contemplate a case of post-combustion capture where $\mathrm{CO}_{2}$ constitutes $15 \%$ of the feed gas $\left(\tilde{P}_{\mathrm{CO}_{2} \text {,feed }}=0.15\right)$, as is similar to the flue gas composition at coal-fired power plants. ${ }^{55} \mathrm{We}$ initially neglect the fraction of $\mathrm{CO}_{2}$ that is removed from the feed gas $(\alpha)$, and in this case $\alpha=0$ (configurations containing cathodic absorption) or $\alpha \geq 0$ (configurations lacking cathodic absorption). While such conditions deviate from practical operation, they enable clear 
identification of performance trends. Further, we hold certain parameter values constant, such as the stoichiometric coefficients of the reactions $(n=2$ and $q=1)$, the state of charge swing $\left(\Delta x_{\mathrm{a}}=\right.$ $0.5)$, and the binding constant for the deactivated species $\left(\ln \left(K_{\mathrm{g}, 2}\right)=-7\right)$. These assumptions are relaxed later in this work, and within the SI, to elucidate the impacts of additional properties.

For this post-combustion capture case, Figure 4(a) shows the impact of the $\mathrm{CO}_{2}$ binding affinity for $\mathrm{R}^{n-}\left(K_{\mathrm{g}, 1}\right)$ and relative solubility of $\mathrm{CO}_{2}\left(\widetilde{H}_{\mathrm{CO}_{2}}\right)$ on the thermodynamic efficiency for each configuration. For all configurations, the $\mathrm{CO}_{2}$ partial pressure in the recovered product is larger than that in the feed gas, and thus there is an unfavorable pressure difference. Accordingly, $K_{\mathrm{g}, 1}$ must be high enough to overcome this pressure difference, $\widetilde{P}_{\mathrm{CO}_{2}, 1}-\widetilde{P}_{\mathrm{CO}_{2}, 3}$, such that $\Delta x_{\mathrm{CO}_{2}}>0$. While $K_{\mathrm{g}, 1}$ must be high enough to overcome this pressure gradient, values that are too high can reduce the thermodynamic efficiency. As $K_{\mathrm{g}, 1}$ increases, more energy is required to disrupt the stronger binding of $\mathrm{CO}_{2}$. This presents as the difference between the standard reduction potentials between the $\mathrm{R} / \mathrm{R}^{n-}$ and $\mathrm{R}\left(\mathrm{CO}_{2}\right)_{q} / \mathrm{R}\left(\mathrm{CO}_{2}\right)_{q}^{n-}$ redox couples (Equation 12). However, for configurations that employ cathodic absorption (i.e., 2-stage system and 3-stage system with cathodic absorption), higher $K_{\mathrm{g}, 1}$ values lead to enhanced removal of the electrochemical product, $\mathrm{R}^{n-}$, at the cathode via the absorption reaction. Therefore, the cathode potential is shifted more positive as $K_{\mathrm{g}, 1}$ increases, allowing these configurations to overcome the increased standard reduction potential difference, $E_{2,0}-E_{1,0}$. As such, the 2-stage system and the 3 -stage system with cathodic absorption are insensitive or less sensitive to $K_{\mathrm{g}, 1}$, respectively. For configurations without cathodic absorption (i.e., 4-stage system and 3-stage system with anodic desorption), the extent of $\mathrm{R}^{n-}$ removal at the cathode (leading to a favorable Nernstian shift) is not sufficient to 
overcome the standard reduction potential difference that grows as $K_{\mathrm{g}, 1}$ increases. Therefore, the 4-stage system and 3-stage system with anodic desorption are more sensitive to $K_{\mathrm{g}, 1}$ values.

Low $\widetilde{H}_{\mathrm{CO}_{2}}$ values can also reduce the thermodynamic efficiency. When $\widetilde{H}_{\mathrm{CO}_{2}}$ is small, there is a lower dissolved $\mathrm{CO}_{2}$ concentration remaining in the electrolyte after $\mathrm{CO}_{2}$ release and degasification. For configurations that do not directly feed $\mathrm{CO}_{2}$-rich gas to the cathode, less $\mathrm{CO}_{2}$ enters the cathode and consequently less $\mathrm{CO}_{2}$ binding can occur. Therefore, the Nernstian shift at the cathode is less positive when $\widetilde{H}_{\mathrm{CO}_{2}}$ is small. More importantly, when $\widetilde{H}_{\mathrm{CO}_{2}}$ is small and $\mathrm{CO}_{2}$ is not continuously removed from the anode, there is a large pressure build-up in the anodic half-cell as the $\mathrm{CO}_{2}$ release reaction occurs, which is shown in Figure 5. This unfavorably shifts the equilibrium of the release reaction, and thus the Nernstian shift at the anode is less negative as compared to configurations where $\mathrm{CO}_{2}$ is removed from the anode (degasification). Although low $\widetilde{\mathrm{H}}_{\mathrm{CO}_{2}}$ may be energetically inefficient for these configurations, these systems may be beneficial for producing pressurized $\mathrm{CO}_{2}$ streams ${ }^{30}$ Configurations which incorporate both anodic desorption and cathodic absorption, can theoretically achieve $100 \%$ thermodynamic efficiency while being insensitive to thermodynamic properties. Overall, it is apparent from Figure 4(a) that employment of cathodic absorption and/or anodic desorption can increase the thermodynamic efficiency. These observations for thermodynamic efficiency, and how it trends with binding strength and relative $\mathrm{CO}_{2}$ solubility, are in general agreement with prior work. ${ }^{28,29,52}$

Thermodynamic properties also affect the faradaic efficiency. The impacts of $K_{\mathrm{g}, 1}$ and $\widetilde{H}_{\mathrm{CO}_{2}}$ on this efficiency are shown in Figure 4(b). In this specific demonstration, the faradaic efficiency curves are the same for all four configurations. The curves begin to deviate for configurations that employ cathodic absorption when the $\mathrm{CO}_{2}$ capture fraction is nonzero (as shown in the Figure $\mathrm{S} 7$ ). As previously discussed, $K_{\mathrm{g}, 1}$ must be high enough to overcome the $\mathrm{CO}_{2}$ partial pressure difference 
across the electrochemical cell. This occurs at the point where the faradaic efficiency crosses the $x$-axis. Above this point, low $K_{\mathrm{g}, 1}$ values penalize the faradaic efficiency since the extent of $\mathrm{CO}_{2}$ binding is much lower than fraction of capture species that is activated via reduction. As $K_{\mathrm{g}, 1}$ increases, efficiency increases and, ultimately, plateaus as the portion of the activated capture species that binds $\mathrm{CO}_{2}$ approaches $100 \%$. This indicates that a further increase in $K_{\mathrm{g}, 1}$ will no longer benefit the system in terms of this maximum faradaic efficiency measure. High $\widetilde{H}_{\mathrm{CO}_{2}}$ values also penalize the faradaic efficiency simply because a greater fraction of $\mathrm{CO}_{2}$ that is released will remain dissolved in solution.
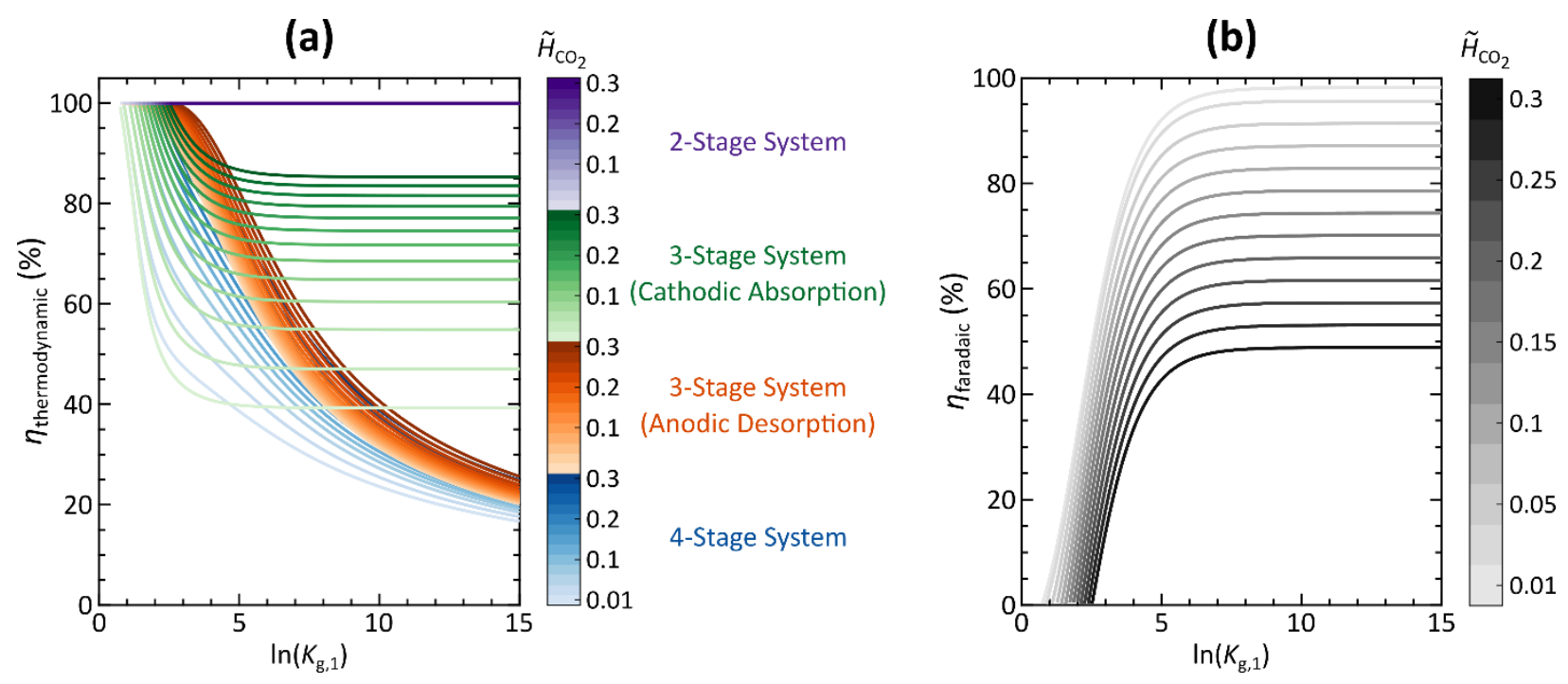

Figure 4. Thermodynamic $\left(\eta_{\text {thermodynamic }}\right)$ and faradaic efficiencies $\left(\eta_{\text {faradaic }}\right)$ for a postcombustion capture system with $\geq 0 \% \mathrm{CO}_{2}$ capture $(\alpha \geq 0)$, where $\widetilde{P}_{\mathrm{CO}_{2} \text {, feed }}=0.15$ and $\widetilde{P}_{\mathrm{CO}_{2} \text {,raf }} \leq$ 0.15. Plot (a) shows distinct thermodynamic efficiency vs. $\ln \left(K_{\mathrm{g}, 1}\right)$ curves for each configuration and (b) shows faradaic efficiency vs. $\ln \left(K_{\mathrm{g}, 1}\right)$ which applies to all four configurations. The relative $\mathrm{CO}_{2}$ solubility, $\widetilde{\mathrm{H}}_{\mathrm{CO}_{2}}$, is varied as the color saturation. The constant parameter values for this demonstration are as follows: $n=2, q=1, \Delta x_{\mathrm{a}}=0.5, \ln \left(K_{\mathrm{g}, 2}\right)=-7$, and $T=298.15 \mathrm{~K}$. 


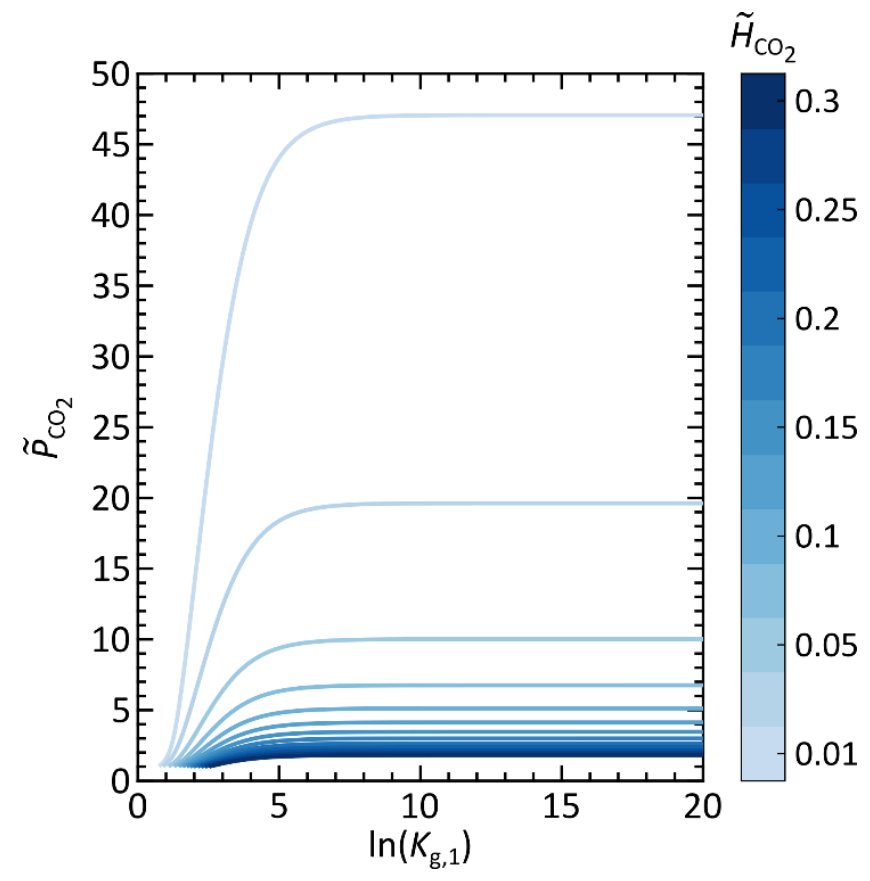

Figure 5. Dimensionless $\mathrm{CO}_{2}$ partial pressure following anodic oxidation vs. $\ln \left(K_{\mathrm{g}, 1}\right)$ for postcombustion capture in a 4-stage system with $\geq 0 \% \mathrm{CO}_{2}$ capture $(\alpha \geq 0)$, where $\tilde{P}_{\mathrm{CO}_{2} \text {, feed }}=0.15$ and $\tilde{P}_{\mathrm{CO}_{2} \text {,raf }} \leq 0.15$. The relative $\mathrm{CO}_{2}$ solubility, $\widetilde{H}_{\mathrm{CO}_{2}}$, is varied as the color saturation. The constant parameter values for this demonstration are as follows: $n=2, q=1, \Delta x_{\mathrm{a}}=0.5, \ln \left(K_{\mathrm{g}, 2}\right)=-7$, and $T=298.15 \mathrm{~K}$.

\subsection{Combined Efficiency: The Tradeoff Between Thermodynamic and Faradaic Efficiency}

From Figures 4(a) and 4(b), it is apparent that there is a tradeoff between the thermodynamic and faradaic efficiencies. Low $K_{\mathrm{g}, 1}$ maximizes the thermodynamic efficiency whereas high $K_{\mathrm{g}, 1}$ maximizes the faradaic efficiency. From the colored lines, we can also see that low $\widetilde{H}_{\mathrm{CO}_{2}}$ maximizes the faradaic efficiency and high $\widetilde{H}_{\mathrm{CO}_{2}}$ maximizes the thermodynamic efficiency. We define a metric here to account for this tradeoff, called the combined efficiency $\left(\eta_{\text {combined }}\right)$, which is defined in Equation 21.

$$
\eta_{\text {combined }}=\eta_{\text {thermodynamic }} \times \eta_{\text {faradaic }}
$$

A system that adequately balances the thermodynamic and faradaic efficiencies by maximizing the combined efficiency may be successful due to a balance of how efficiently the process uses 
energy and materials. Thus, by using this combined efficiency metric, we can begin to understand what success may look like for electrochemical $\mathrm{CO}_{2}$ separation systems that use soluble, redoxactive capture species.

Figure 6 shows the combined efficiency for each of the four configurations and how this is impacted by $K_{\mathrm{g}, 1}$ and $\widetilde{H}_{\mathrm{CO}_{2}}$. Again, this analysis incorporates a representative feed concentration $\left(\tilde{P}_{\mathrm{CO}_{2}, \text { feed }}=0.15\right)$ for a post-combustion capture process. However, it is imposed here that more than $90 \%$ of $\mathrm{CO}_{2}$ is captured from the feed gas, which is a typical threshold in post-combustion applications. ${ }^{6,56}$ More specifically, when cathodic absorption is employed, it is assumed that the dimensionless partial pressure of $\mathrm{CO}_{2}$ in the feed gas is reduced from 0.15 to 0.015 , such that $\alpha=$ 0.914 (91.4\% capture) according to Equation 18. With no cathodic absorption, we cannot assume a constant capture fraction due to the assumption that absorption occurs in a countercurrent flow unit. The amount of $\mathrm{CO}_{2}$ removed from the feed gas stream is determined based upon the equilibrium between the feed gas exiting and the liquid electrolyte entering the absorption unit; therefore, this quantity will change with the $\mathrm{CO}_{2}$ binding affinity, $K_{\mathrm{g}, 1}$. However, we ensure that $\alpha \geq 0.914$, by only including data points where $\tilde{P}_{\mathrm{CO}_{2} \text {,raf }} \leq 0.015$. The dotted lines in Figure 6 represent binding coefficient values where $\widetilde{P}_{\mathrm{CO}_{2} \text {,raf }}>0.015$, and thus the binding affinities are not large enough to achieve sufficient $\mathrm{CO}_{2}$ capture.

For system configurations with no cathodic absorption (4-stage system and 3-stage system with anodic desorption), the combined efficiency is maximized at more intermediate values of $K_{\mathrm{g}, 1}$. Comparatively, with employment of cathodic absorption (2-stage system and 3-stage system with cathodic absorption), the combined efficiency is maximized at larger values of $K_{\mathrm{g}, 1}$. This is because the thermodynamic efficiency of these systems is less sensitive or insensitive to $K_{\mathrm{g}, 1}$, and thus the faradaic efficiency dominates the tradeoff between these two metrics. Therefore, the combined 
efficiency is maximized at larger values of $K_{\mathrm{g}, 1}$, but plateaus such that further increases in the binding strength no longer improve the thermodynamics of the system.

Differences in the combined efficiency curves also arise depending on whether a configuration with anodic desorption capabilities is adopted. Without anodic desorption (4-stage system and 3stage system with cathodic absorption), the combined efficiency is maximized at intermediate values of $\widetilde{H}_{\mathrm{CO}_{2}}$. In these cases, the thermodynamic efficiency is relatively sensitive to $\widetilde{H}_{\mathrm{CO}_{2}}$ due to the large pressure increases that can occur at the anode, which unfavorably shifts the desorption equilibrium. Because of this, there is a balanced tradeoff between thermodynamic efficiency (maximized at high $\widetilde{H}_{\mathrm{CO}_{2}}$ ) and faradaic efficiency (maximized at low $\widetilde{H}_{\mathrm{CO}_{2}}$ ) leading to intermediate $\widetilde{H}_{\mathrm{CO}_{2}}$ values maximizing the combined efficiency. When anodic desorption is employed (2-stage system and 3-stage system with anodic desorption), the thermodynamic efficiency is less sensitive or insensitive to $\widetilde{H}_{\mathrm{CO}_{2}}$ and the tradeoff is dominated by the faradaic efficiency. Therefore, the combined efficiency is maximized at small values of $\widetilde{H}_{\mathrm{CO}_{2}}$.

Imposing a minimum capture fraction, $\alpha$, also impacts the combined efficiency. The specific effect of $\alpha$, however, will be dependent upon system configuration. As previously described, for systems lacking cathodic absorption, the partial pressure of $\mathrm{CO}_{2}$ following cathodic reduction must be low enough to achieve a specified capture fraction. Figures 6(a) and 6(b) demonstrate how lower $K_{\mathrm{g}, 1}$ values are no longer feasible for these configurations when a capture fraction is imposed. This infeasible operating regime will grow as $\alpha$ is further increased. For systems with cathodic absorption, the combined efficiency curves are shifted towards larger $K_{\mathrm{g}, 1}$ values when a capture fraction is imposed as compared to systems lacking cathodic absorption. This is due to the counter-current flow assumption in the absorption unit, which is not made for cathodic absorptionbased systems. During the cathodic absorption step, specifically when $\alpha>0, \widetilde{P}_{\mathrm{CO}_{2}}$ decreases near 
the cathode as the state of charge increases until it reaches $\widetilde{P}_{\mathrm{CO}_{2} \text {,raf. As a result, the combined }}$ efficiency curves are shifted towards larger $K_{\mathrm{g}, 1}$ values, which can be observed by comparing Figures 6(c) and 6(d) to Figures S9(c) and S9(d) in the SI, for which $\alpha=0$. Overall, as $\alpha$ increases, stronger binding and thus larger $K_{\mathrm{g}, 1}$ values are required for all four configurations.
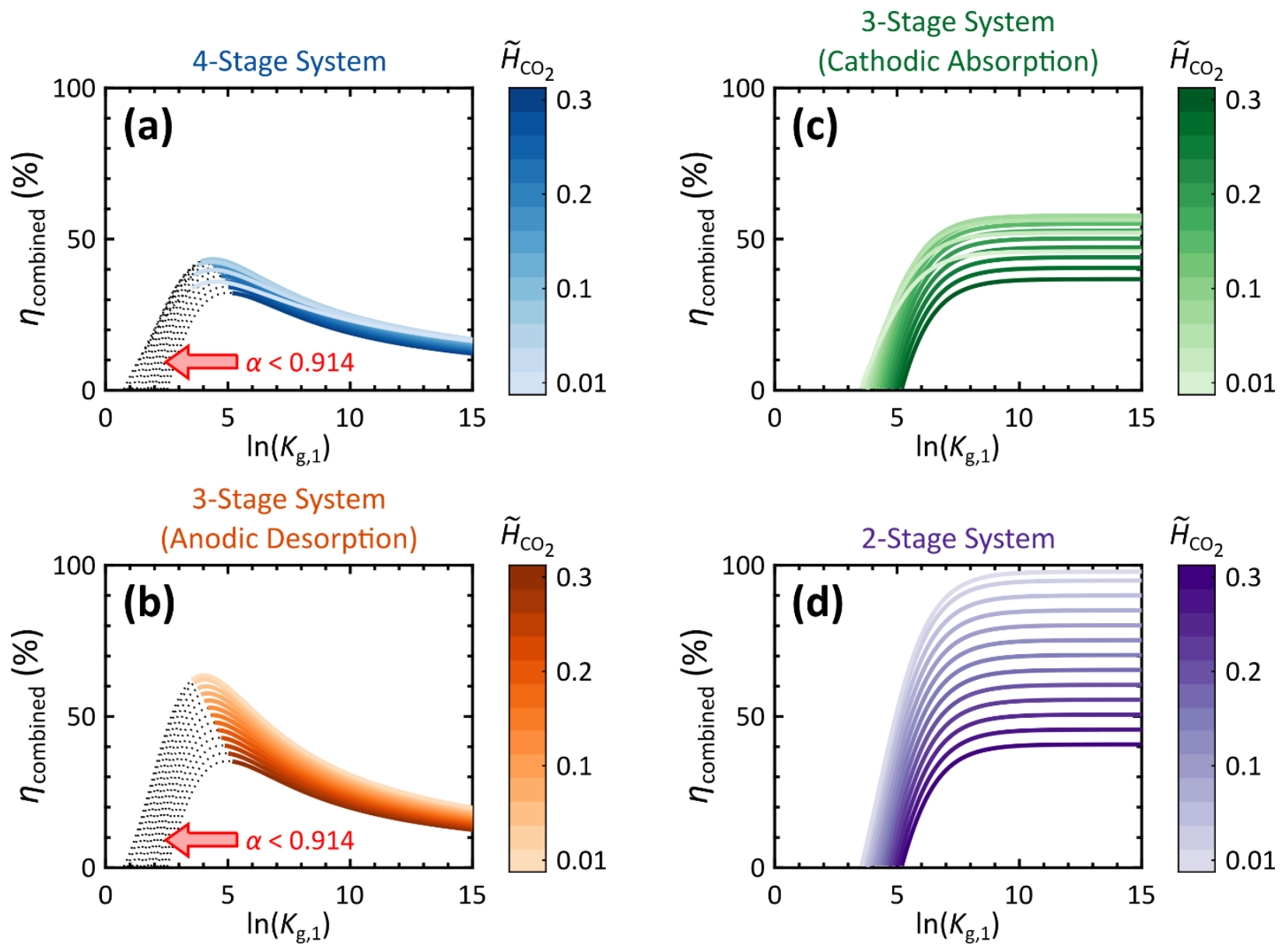

Figure 6. Combined efficiencies ( $\eta_{\text {combined }}$ ) for a post-combustion capture system with $\geq 91.4 \%$ $\mathrm{CO}_{2}$ capture $(\alpha \geq 0.914)$, where $\widetilde{P}_{\mathrm{CO}_{2} \text {,feed }}=0.15$ and $\tilde{P}_{\mathrm{CO}_{2} \text {,raf }} \leq 0.015$. The black dotted lines represent infeasible operating regimes given the $\alpha$ constraint. The relative $\mathrm{CO}_{2}$ solubility, $\widetilde{H}_{\mathrm{CO}_{2}}$, is varied as the color saturation. The constant parameter values for this demonstration are as follows: $n=2, q=1, \Delta x_{\mathrm{a}}=0.5, \ln \left(K_{\mathrm{g}, 2}\right)=-7$, and $T=298.15 \mathrm{~K}$. 


\subsection{Benchmarking Existing Capture Materials}

To demonstrate how measurable molecular properties can be compared to the combined efficiency metric, we make use of previously reported data. Several redox-active molecules have been identified and experimentally evaluated as candidate capture species for electrochemical $\mathrm{CO}_{2}$ capture. ${ }^{38-49,57}$ In one study, DuBois et al. reported $\mathrm{CO}_{2}$ binding properties of five quinones. ${ }^{38}$ Table 1 compares the binding coefficient of three of these quinone species: 2,3-dichloro-5,6dicyano-1,4-benzoquinone (DDBQ), 2,3,5,6-tetrachloro-1,4-benzoquinone (TCBQ), and 2,5-ditert-butyl-1,4-benzoquinone (DtBBQ).$^{38}$ These were all measured in an acetonitrile solution containing $0.3 \mathrm{~N}$ tetraethylammonium tetrafluoroborate. In Table 1 , the reported binding coefficients relative to dissolved $\mathrm{CO}_{2}\left(K_{1}\right)$ are converted to gas-phase absorption values $\left(K_{\mathrm{g}, 1}\right)$ using the reported solubility for $\mathrm{CO}_{2}$ in the electrolyte of $4.12 \times 10^{-4} \mathrm{M} / \mathrm{mmHg}(0.309 \mathrm{M} / \mathrm{bar})$. The $K_{\mathrm{g}, 1}$ values of the three molecules shown in Table 1 are compared to combined efficiency curves for a 2-stage system and 3-stage system with anodic desorption in Figure 7. Results for the other two configurations follow similar trends with $K_{\mathrm{g}, 1}$ depending on whether cathodic absorption is employed. This figure demonstrates how measured molecular properties can be mapped to the combined efficiency curves to assess the potential success of capture molecule and electrolyte pairs. If $K_{\mathrm{g}, 1}$ is too low (e.g., DDBQ), the capture molecule is not predicted to efficiently separate $\mathrm{CO}_{2}$ in any configuration. Higher $K_{\mathrm{g}, 1}$ values (e.g., TCBQ and DtBBQ) are projected to work well for configurations that employ cathodic absorption, such as a 2-stage system. Comparatively, more intermediate $K_{\mathrm{g}, 1}$ values are projected to be successful for configurations that do not employ cathodic absorption (e.g., 3-stage system with anodic desorption). Molecules with a binding strength between that of DDBQ and TCBQ might be better suited for these configurations. 
Table 1. Reported binding coefficients $\left(K_{1}\right)$ for three quinone species, ${ }^{38}$ and derived gas-phase binding coefficients $\left(K_{\mathrm{g}, 1}\right)$. These binding coefficients, $K_{1}$, were measured in an acetonitrile solvent with $0.3 \mathrm{~N}$ tetraethylammonium tetrafluoroborate as the supporting salt. Here, we use the $\mathrm{CO}_{2}$ solubilty (defined by $\mathrm{H}_{\mathrm{CO}_{2}}$ ) of this electrolyte, which was reported as $4.12 \times 10^{-4} \mathrm{M} / \mathrm{mmHg}$ $(0.309 \mathrm{M} / \mathrm{bar}){ }^{38}$ The reported potentials, $E_{1 / 2}$, represents the half-wave potential (or standard reduction potential) of the $2^{\text {nd }}$ electron transfer event.

\begin{tabular}{|c|c|c|c|c|c|}
\hline & Capture Species & $K_{1}$ & $K_{\mathrm{g}, 1}=\left(H_{\mathrm{CO}_{2}} \frac{P_{0}}{\left[C_{0}\right]}\right)^{q} K_{1}$ & $\ln \left(K_{g, 1}\right)$ & $E_{1 / 2}$ \\
\hline (1) & $\begin{array}{l}\text { 2,3-dichloro-5,6-dicyano- } \\
\text { benzoquinone (DDBQ) }\end{array}$ & 3.6 & 1.1 & 0.1 & -0.25 vs. SCE \\
\hline (2) & $\begin{array}{c}\text { Tetrachlorobenzoquinone } \\
\text { (TCBQ) }\end{array}$ & 5600 & 1730 & 7.5 & -0.72 vs. SCE \\
\hline (3) & $\begin{array}{c}\text { 2,5-di-tert-butyl- } \\
\text { benzoquinone (DtBBQ) }\end{array}$ & $1.1 \times 10^{15}$ & $3.4 \times 10^{14}$ & 33.5 & -1.46 vs. SCE \\
\hline
\end{tabular}
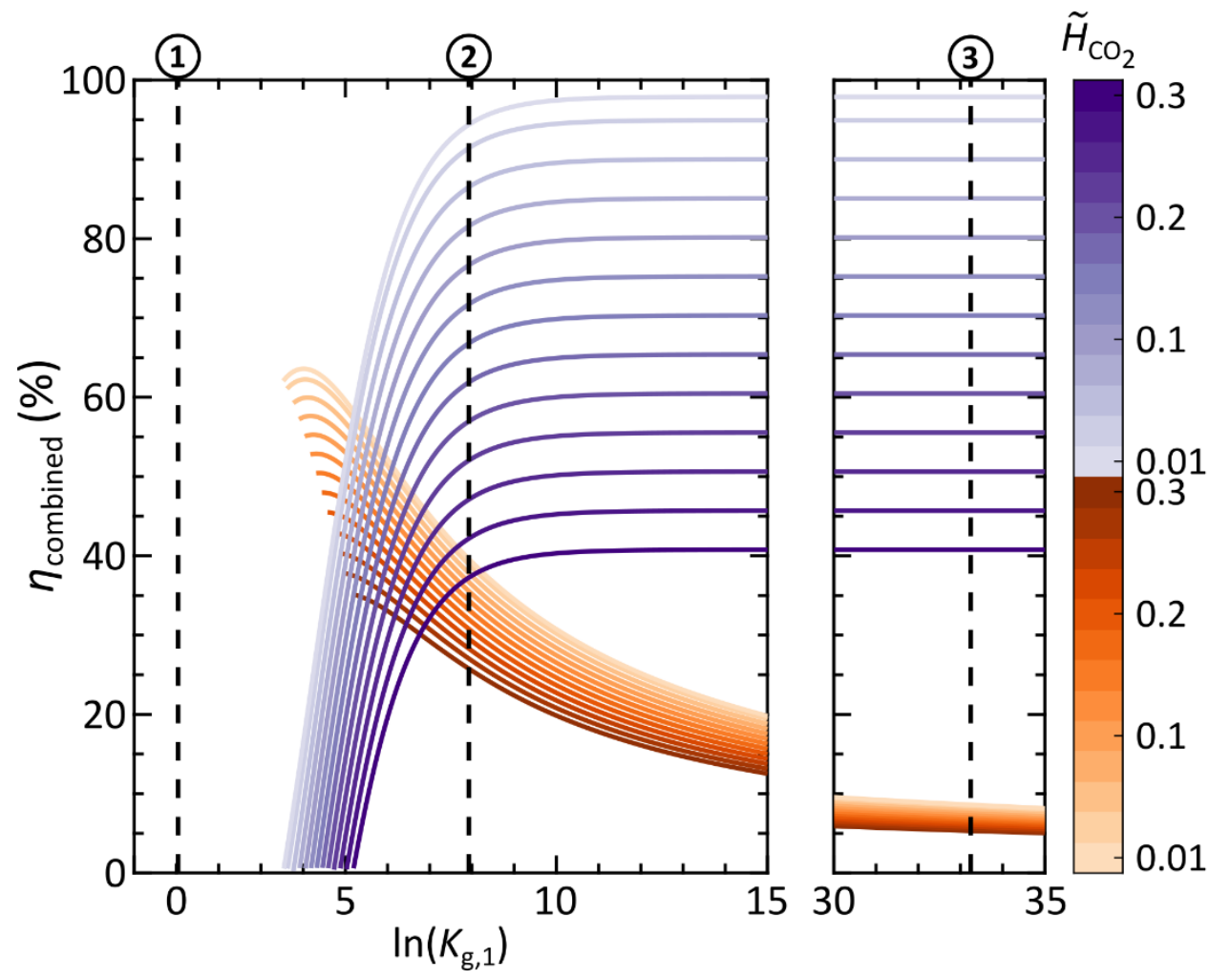

2-Stage System

Figure 7. A comparison of $K_{\mathrm{g}, 1}$ values derived from experimental data (Table 1) to the combined efficiency curves for a 2 -stage system (purple) and 3-stage system with anodic desorption (orange). This modeled data is for a post-combustion application with $\geq 91.4 \% \mathrm{CO}_{2}$ capture $(\alpha \geq 0.914)$ while keeping certain parameters constant $n=2, q=1, \Delta x_{\mathrm{a}}=0.5, \ln \left(K_{g, 2}\right)=-7$, and $T=298.15$ K. 
From this work, a molecule with stronger binding such as DtBBQ appears well-suited for a system with cathodic absorption (e.g., two-stage system). However, this thermodynamic modeling framework is limited in that it does not consider how other important molecular properties trend with $K_{\mathrm{g}, 1}$. As an example, for a given class of molecules, the reduction potential tends to trend more negatively as the binding coefficient increases, which can be seen in Table 1 for the three species listed. When the reduction potential is more negative than that of the oxygen $\left(\mathrm{O}_{2}\right)$ reduction reaction (ca. $-0.8 \mathrm{~V}$ vs. $\mathrm{SCE}^{58}$ ), this can lead to the reduction of $\mathrm{O}_{2}$ either heterogeneously at the electrode surface or homogeneously with reduced capture molecules. This can further reduce the faradaic efficiency from its predicted value and more importantly, lead to side products which are destructive to cell components. Thus, depending upon the class of capture species, it may be beneficial to operate at more intermediate binding coefficient values, such as that of TCBQ, where the combined efficiency for cathodic absorption-based systems is still sufficiently high.

Another factor that must be considered is the capture species solubility, which can heavily influence the success of the molecule. For the species shown in Table 1, the solubilities were not reported, which is why molecules 1-3 (from Table 1) are represented with vertical lines in Figure 7. However, the solubility of capture molecules will impact the maximum operating capture species concentration, $\left[R_{0}\right]$. The $\left[R_{0}\right]$ chosen for operation will define the relatively solubility of $\mathrm{CO}_{2}, \widetilde{H}_{\mathrm{CO}_{2}}$, which in turn affects both the thermodynamic and faradaic efficiencies (and thus the combined efficiency). As an example, the combined efficiency of a 2-stage system decreases from $98 \%$ to $41 \%$ when $\widetilde{H}_{\mathrm{CO}_{2}}$ is increased from 0.01 to 0.3 . Electrolyte composition, including factors such as solvent, supporting salt, and salt concentration, will have an impact on both capture species and $\mathrm{CO}_{2}$ solubility. Additionally, this thermodynamic study assumes that the solubility of capture species remains constant across all states. In reality, there may be differences in solubility between 
the reduced and neutral states of these species, as well as the $\mathrm{CO}_{2}$-bound and unbound state. All these factors impacting solubilities must be considered when designing and evaluating these systems.

\subsection{Determination of Effective Binding Constants}

Thus far, calculations have assumed constant values for state of charge swing $\left(\Delta x_{\mathrm{a}}=0.5\right)$, feed $\mathrm{CO}_{2}$ partial pressure $\left(\tilde{P}_{\mathrm{CO}_{2}, \text { feed }}=0.15\right)$, and binding constant for the deactivated species $\left(K_{\mathrm{g}, 2}=10^{-}\right.$ ${ }^{7}$ ). Effective values of the binding coefficient, however, will be dependent upon these parameters. Here, we determine effective binding coefficients, $K_{\mathrm{g}, 1}^{\mathrm{eff}}$, for both post-combustion capture $\left(\tilde{P}_{\mathrm{CO}_{2}, \text { feed }}=0.15\right)$ and DAC $\left(\tilde{P}_{\mathrm{CO}_{2}, \text { feed }}=4.1 \times 10^{-4}\right)$ applications while relaxing these constant parameter assumptions. For systems with no cathodic absorption (4-stage system and 3-stage system with anodic desorption), $K_{\mathrm{g}, 1}^{\mathrm{eff}}$ is determined as the $K_{\mathrm{g}, 1}$ value that maximizes the combined efficiency curve. For systems with cathodic absorption (2-stage system and 3-stage system with cathodic absorption), $K_{\mathrm{g}, 1}^{\mathrm{eff}}$ is defined as the knee of the combined efficiency curve, above which the efficiency levels out. This knee point is estimated using the Kneedle algorithm. ${ }^{59}$ For these configurations, it is important to note that $K_{\mathrm{g}, 1}$ values above $K_{\mathrm{g}, 1}^{\mathrm{eff}}$ can also achieve high efficiencies and therefore would be suitable.

In Figure $8, K_{\mathrm{g}, 1}^{\mathrm{eff}}$ is plotted against $\Delta x_{\mathrm{a}}$ and $K_{\mathrm{g}, 2}$ for both post-combustion capture and DAC scenarios. Figure $8(\mathrm{a})$ looks at $K_{\mathrm{g}, 1}^{\mathrm{eff}}$ as a function of system configuration and state of charge swing, $\Delta x_{\mathrm{a}}$, for post-combustion capture. In accordance with trends observed in prior sections, configurations containing cathodic absorption (e.g., 2-stage system) will require higher binding coefficients as compared to configurations lacking this feature. For all configurations, employing a higher state of charge swing enables lower effective binding affinities. This is because a larger fraction of the capture species is activated and available to bind $\mathrm{CO}_{2}$, and therefore relatively 
weaker binding is sufficient. Operating at higher $\Delta x_{\mathrm{a}}$ may also lead to higher combined efficiencies, particularly for higher $\widetilde{H}_{\mathrm{CO}_{2}}$ values (as shown in Figure S20(a)). However, this analysis does not consider increases in the mass transport overpotential that accompany higher $\Delta x_{\mathrm{a}}$ values which can reduce efficiency. In contrast, when operating at low $\Delta x_{\mathrm{a}}$ values, a smaller fraction of the capture species is activated and available to bind $\mathrm{CO}_{2}$. Stronger binding is necessary for these cases and $K_{\mathrm{g}, 1}^{\mathrm{eff}}$ is more sensitive to the relative $\mathrm{CO}_{2}$ solubility, $\widetilde{H}_{\mathrm{CO}_{2}}$. As $\Delta x_{\mathrm{a}}$ decreases towards the vertical asymptote (ca. $\Delta x_{\mathrm{a}}=0.01-0.3$ for $\widetilde{H}_{\mathrm{CO}_{2}}=0.01-0.3$ ), there is a sharp drop-off in the achievable combined efficiencies (Figure S20(a)). Thus, operating near this regime would lead to infeasible performance.

In Figure $8(\mathrm{~b}), \Delta x_{\mathrm{a}}$ is held constant at 0.5 while $K_{\mathrm{g}, 2}$ is varied, where $K_{\mathrm{g}, 2}$ represents how strongly the deactivated capture species (R) holds onto $\mathrm{CO}_{2}$. When $K_{\mathrm{g}, 2}$ is sufficiently low (ca. $\ln \left(K_{\mathrm{g}, 2}\right)<$ -2.5), changes in $K_{\mathrm{g}, 1}^{\mathrm{eff}}$ values as well as achievable efficiencies (Figure S20(b)) are negligible. However, when $K_{\mathrm{g}, 2}$ increases past this threshold, such the quantity of $\mathrm{CO}_{2}$ which remains bound to $\mathrm{R}$ is non-negligible, $K_{\mathrm{g}, 1}^{\mathrm{eff}}$ increases sharply. Similar to the what was observed with $\Delta x_{\mathrm{a}}$, the achievable combined efficiencies trend towards zero as $K_{\mathrm{g}, 2}$ approaches this asymptote (as shown in Figure $\mathrm{S} 20(\mathrm{~b}))$. Thus, $\ln \left(K_{\mathrm{g}, 2}\right)$ should be higher than -ca. 2.5 in this post-combustion capture case to ensure efficient operation.

Figures $8(\mathrm{c})$ and $8(\mathrm{~d})$ look at $K_{\mathrm{g}, 1}^{\text {eff }}$ as a function of $\Delta x_{\mathrm{a}}$ and $K_{\mathrm{g}, 2}$ respectively for DAC, where the inlet concentration of $\mathrm{CO}_{2}$ is reduced by three orders of magnitude. It is also important to note that $\alpha \geq 0.5$ for this case, which is within the typical range of current DAC technologies. ${ }^{6}$ Specifically, we assume $\alpha=0.5$ for the 2 -stage system (contains cathodic absorption) and we ensure that $\alpha \geq$ 0.5 for the 3-stage system with anodic desorption (lacks cathodic absorption). Observed trends 
with $\Delta x_{\mathrm{a}}$ and $K_{\mathrm{g}, 2}$ are qualitatively similar to the post-combustion capture case shown in Figures 8(a) and 8(b). Accordingly, the ranges of these variables that lead to inefficient operation are comparable, which can be observed in Figures S20(c) and S20(d). A key difference between these two applications is that DAC requires capture molecules with higher $\mathrm{CO}_{2}$ binding affinity. The lower inlet concentrations of $\mathrm{CO}_{2}$ in DAC unfavorably shifts the equilibrium of the absorption reaction (Equation 2). Stronger binding is necessary to shift this equilibrium towards the absorbed product, $\mathrm{R}\left(\mathrm{CO}_{2}\right)_{q}^{n-}$, leading to larger effective binding values as compared to post-combustion capture. Additionally, $K_{\mathrm{g}, 1}^{\text {eff }}$ curves for the 2-stage system are shifted closer to the curves for the 3 stage system with anodic desorption due to the lower imposed $\alpha$ value used for DAC as compared to post-combustion capture. If $\alpha$ were increased, $K_{\mathrm{g}, 1}^{\text {eff }}$ values for the 2 -stage system would be shifted towards higher values. A higher capture fraction may also impact effective binding values for the 3-stage configuration with anodic desorption, but to a much lesser extent.

Overall, effective binding coefficient values, $K_{\mathrm{g}, 1}^{\text {eff }}$, and achievable combined efficiencies will be dependent upon molecular properties (e.g., $K_{\mathrm{g}, 2}$ and $\widetilde{H}_{\mathrm{CO}_{2}}$ ), operating factors (e.g., $\Delta x_{\mathrm{a}}$ ) and process application (e.g., post-combustion capture or DAC). To this end, figures 8(a)-(d) explore the impact of these properties on $K_{\mathrm{g}, 1}^{\mathrm{eff}}$ and can be used to assess the potential success of redoxactive capture species and electrolyte pairs. After transforming the binding coefficient relative to dissolved $\mathrm{CO}_{2}\left(K_{1}\right)$ to the gas-phase binding coefficient $\left(K_{\mathrm{g}, 1}\right)$, these results can be used to determine whether $K_{\mathrm{g}, 1}$ falls within the proposed effective range. This can also provide insight as to what system configuration a carrier species and electrolyte pair would be best-suited for, specifically a configuration with or without cathodic absorption. Finally, these maps of $K_{\mathrm{g}, 1}^{\mathrm{eff}}$, in 
combination with Figures S20(a)-S20(d), can be used to identify certain molecular properties and operating factors which may lead to low process efficiencies.

While the efficiency curves and $K_{\mathrm{g}, 1}^{\mathrm{eff}}$ maps shown here are specific to capture species that undergo 2 electron transfers $(n=2)$ and can bind 1 molecule of $\mathrm{CO}_{2}(q=1)$, we also explore other cases in this work. The SI contains figures for thermodynamic, faradaic, and combined efficiencies for the following cases: $n=1$ and $q=1$ (Section S.4.1), $n=2$ and $q=1$ (Section S.4.2), and $n=$ 2 and $q=2$ (Section S.4.3). These scenarios are explored for both post-combustion capture and DAC. Further, Section S.5 presents the associated combined efficiencies for the $K_{\mathrm{g}, 1}^{\text {eff }}$ values shown in Figure 8, as well as $K_{\mathrm{g}, 1}^{\text {eff }}$ design maps and associated combined efficiencies for a capture molecule characterized by $n=2$ and $q=2$. 

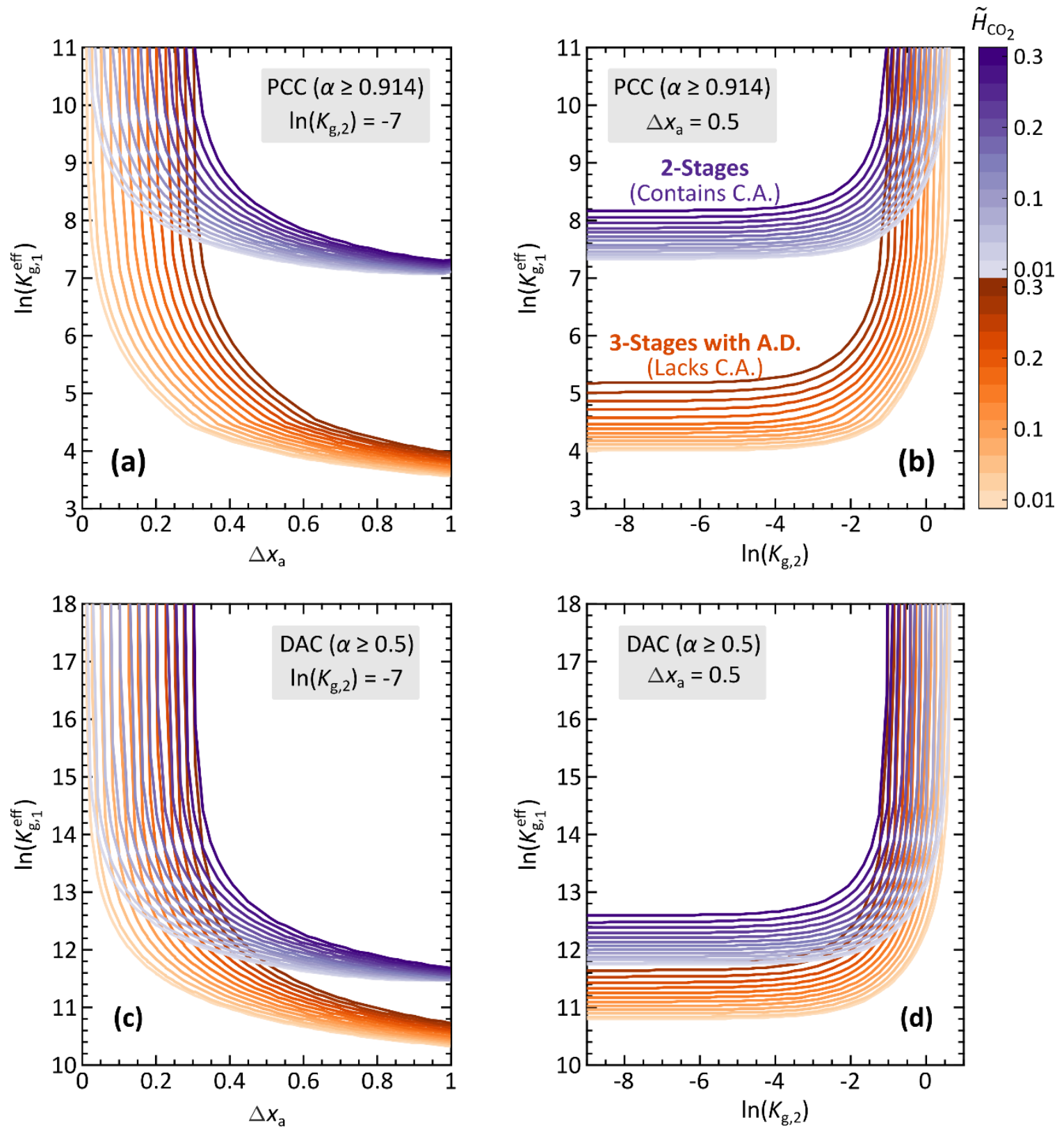

Figure 8. Effective $K_{g, 1}$ values $\left(K_{\mathrm{g}, 1}^{\text {eff }}\right)$ for both post-combustion capture (PCC) and direct air capture (DAC) applications, as determined from the combined efficiency curves. Results are shown for one system configuration that contains cathodic absorption, C.A. (2-stage system) and one that lacks cathodic absorption (3-stage system with anodic desorption, A.D.). For configurations without cathodic absorption, binding affinities $=K_{\mathrm{g}, 1}^{\text {eff }}$ maximize the combined efficiency. Comparatively, when a system contains cathodic absorption, binding affinities $\geq K_{\mathrm{g}, 1}^{\text {eff }}$ will optimize this efficiency. For PCC, (a) shows $\ln \left(K_{\mathrm{g}, 1}^{\mathrm{eff}}\right)$ vs. $\Delta x_{\mathrm{a}}$ and (b) shows $\ln \left(K_{\mathrm{g}, 1}^{\mathrm{eff}}\right)$ vs $\ln \left(K_{\mathrm{g}, 2}\right)$; For DAC, (c) shows $\ln \left(K_{\mathrm{g}, 1}^{\text {eff }}\right)$ vs. $\Delta x_{\mathrm{a}}$ and (b) shows $\ln \left(K_{\mathrm{g}, 1}^{\mathrm{eff}}\right)$ vs $\ln \left(K_{\mathrm{g}, 2}\right)$. For each plot, the relative $\mathrm{CO}_{2}$ solubility, $\widetilde{H}_{\mathrm{CO}_{2}}$, is varied as the color saturation. Each figure contains information about constant parameter values. For all four cases, other constant parameters as follows: $n=2, q$ $=1$, and $T=298.15 \mathrm{~K}$. 


\section{CONCLUSIONS}

We have assessed the impact of several key thermodynamic properties, operating factors, and system properties on the performance of electrochemical $\mathrm{CO}_{2}$ separations with soluble, redoxactive capture species. Extending a thermodynamic modeling framework, ${ }^{52}$ we computed thermodynamic $\left(\eta_{\text {thermodynamic }}\right)$ and faradaic $\left(\eta_{\text {faradaic }}\right)$ efficiencies, which serve as an upper bound on the achievable energy and materials utilization efficiencies, respectively. Here, we demonstrate that a tradeoff exists between these two efficiencies. We have introduced the combined efficiency ( $\left.\eta_{\text {combined }}\right)$, defined as $\eta_{\text {thermodynamic }} \times \eta_{\text {faradaic }}$, as a metric to assess this tradeoff. We propose that capture materials and electrolytes which maximize the combined efficiency metric may be more effective due to an adequate balance between thermodynamic (energetic) and faradiac (material utilization) efficiencies. Using the combined efficiency metric, we have found that effective molecular properties will vary depending upon the system configuration, molecular properties, operating factors, and process application (e.g., postcombustion capture versus DAC).

Implementation of cathodic absorption and/or anodic desorption can increase achievable combined efficiencies. Adoption of a 2-stage system, which contains both cathodic absorption and anodic absorption, permits the highest values of this efficiency metric. Type of configuration also influences how certain molecular properties impact the combined efficiency. First, when considering system configurations which lack cathodic absorption (4-stage system and 3-stage system with anodic desorption), intermediate binding coefficients, $K_{\mathrm{g}, 1}$, maximize the combined efficiency and thus may be more effective. Comparatively, for systems containing cathodic absorption (2-stage system and 3-stage system with cathodic absorption), larger $K_{\mathrm{g}, 1}$ values may be beneficial. This is also dependent upon the capture fraction imposed upon the system. The 
discrepancy between optimal or effective $K_{\mathrm{g}, 1}$ values for these two classes of configuration increases at higher capture fractions. There is also a distinction between system configurations with anodic desorption (2-stage system and 3-stage system with anodic desorption) and without it (4-stage system and 3-stage system with cathodic absorption). Small $\widetilde{H}_{\mathrm{CO}_{2}}$ values maximize the combined efficiency and therefore may be more effective for system configurations containing anodic desorption, whereas intermediate values may be beneficial when there is no anodic desorption in the configuration.

Using the combined efficiency curves, we compute effective $K_{\mathrm{g}, 1}$ values, $K_{\mathrm{g}, 1}^{\text {eff }}$, for both postcombustion and direct air capture applications (Figure 8). We have considered the interplay between $K_{\mathrm{g}, 1}^{\text {eff }}$ and various properties $\left(K_{\mathrm{g}, 2}, \widetilde{H}_{\mathrm{CO}_{2}}\right.$, and $\left.\Delta x_{\mathrm{a}}\right)$, while also providing insight into what system configurations these pairs may be successful in. We also identify regimes that may lead to significant efficiency losses: ca. $\Delta x_{\mathrm{a}}<0.01-0.3$ for $\widetilde{H}_{\mathrm{CO}_{2}}=0.01-0.3$ and $\ln \left(K_{\mathrm{g}, 2}\right)>-2.5$ (when $\left.\Delta x_{\mathrm{a}}=0.5\right)$. These results can serve as a benchmark to which existing capture molecule and electrolyte pairs can be compared to, and furthermore, can guide future design. However, it is important to keep in mind that this analysis does not consider the effects of kinetics, mass transport, and other potential inefficiencies. While binding coefficients are an important design factor, the reaction rates of the binding and release reactions will also have a significant impact on performance. This can influence the feasibility of incorporating cathodic absorption and/or anodic desorption. Relatively slow reactions may hinder the incorporation of a 2-stage system. Kinetic rates of the electrochemical reaction should also be considered, as these will influence the surface overpotentials of the electrode which serve as an additional energetic penalty to the thermodynamic efficiencies predicted in this study. Species solubilities and mass transport properties of each species will also influence the overall rates of the binding/release and 
electrochemical reactions. From this thermodynamic analysis, the 2-stage system may appear optimal due to its ability to achieve high efficiencies. However, for configurations that employ cathodic absorption as such, the electrochemical reactor may be limited by mass transport of $\mathrm{CO}_{2}$ to the electrode-electrolyte interface to ensure the rate of capture species activation is similar to the rate of $\mathrm{CO}_{2}$ transport. This can limit operation of a 2-stage system to low current densities, especially at low $\mathrm{CO}_{2}$ concentrations. Crossover can also diminish performance, specifically for configurations that lack anodic desorption. As shown in Figure 5, the $\mathrm{CO}_{2}$ pressure can significantly increase leading to a larger pressure difference across the cell and higher rates of crossover. Although this study lacks the consideration of such effects, it is still important to consider maximum achievable efficiencies (thermodynamic, faradaic, and combined efficiencies) predicted by thermodynamics, as this sets the upper bound for performance. Finally, while the design of capture species and electrolyte pairs with effective thermodynamic properties $\left(K_{\mathrm{g}, 1}, K_{\mathrm{g}, 2}\right.$, $\widetilde{H}_{\mathrm{CO}_{2}}$ ) are important, the energetics and efficiencies of practical system operation will also be dependent on resistive losses associated with kinetic, ohmic and transport processes that are distinct of each configuration. These factors will be contemplated in future work. 


\section{ASSOCIATED CONTENT}

The Supporting Information is available and free of charge.

List of variables and constants (Section S.1); Detailed derivation of Equations 13 and 15 (Section S.2); Description of the potential computation procedure for all four configurations (Section S.3); Thermodynamic, faradaic, and combined efficiency plots for capture molecules with the following properties: $n=1, q=1 ; n=2, q=1$; and $n=2, q=2$ (Section S.4); Thermodynamic, faradaic, and combined efficiency plots for both post-combustion and DAC applications (Section S.4);

Combined efficiencies at the associated $K_{\mathrm{g}, 1}^{\text {eff }}$ values from Figure 8 (Section S.5); $K_{\mathrm{g}, 1}^{\text {eff }}$ values and associated combined efficiencies for capture molecules with the following properties: $n=2, q=$ 1 and $n=2, q=2$ (Section S.5).

\section{AUTHOR INFORMATION}

\section{Corresponding Authors}

- $\quad$ Fikile R. Brushett - Department of Chemical Engineering, Massachusetts Institute of Technology, Cambridge, Massachusetts 02139, United Stated; orcid.org/0000-0002-73616637; Email: brushett@mit.edu

\section{Authors}

- Lauren E. Clarke - Department of Chemical Engineering, Massachusetts Institute of Technology, Cambridge, Massachusetts 02139, United Stated; orcid.org/0000-0003-47802791; Email: 1clarke@mit.edu

- McLain E. Leonard - Department of Chemical Engineering, Massachusetts Institute of Technology, Cambridge, Massachusetts 02139, United Stated; orcid.org/0000-0003-45725251; Email: mclainl@mit.edu

- T. Alan Hatton - Department of Chemical Engineering, Massachusetts Institute of Technology, Cambridge, Massachusetts 02139, United Stated; orcid.org/0000-0002-4558245X; Email: tahatton@mit.edu 


\section{Author Contributions}

LEC: Conceptualization, Methodology, Validation, Formal analysis, Investigation, Data curation, Writing - original draft, Writing - review \& editing, Visualization. MEL:

Methodology, Writing - original draft, Writing - review \& editing. TAH: Writing - Review \& Editing. FRB: Conceptualization, Resources, Writing - original draft, Writing - review \& editing, Supervision, Funding acquisition.

\section{Notes}

The authors declare no competing financial interest.

\section{ACKNOWLEDGMENTS}

The authors gratefully acknowledge funding support from the Alfred P. Sloan Foundation. We thank Prof. Jenny Yang and Prof. Anastassia Alexandrova from UC Irvine and UCLA, respectively, and members of their research groups for valuable feedback throughout this project. We also thank Alexis M. Fenton, Jr., Alexander Quinn, and Katelyn Ripley of the Brushett Group for fruitful discussions on this work.

\section{NOMENCLATURE}

$\begin{array}{ll}{\left[\mathrm{C}_{0}\right]} & \begin{array}{l}\text { Standard concentration }(1 \mathrm{M}) \\ {\left[\mathrm{CO}_{2}\right]_{\mathrm{T}}}\end{array} \\ E & \begin{array}{l}\text { Total } \mathrm{CO}_{2} \text { concentration in the electrolyte, including physically dissolved } \\ \mathrm{CO}_{2} \text { and } \mathrm{CO}_{2} \text { bound to the capture species }(\mathrm{M})\end{array} \\ E_{\mathrm{dev}} & \text { Electrode potential }(\mathrm{V}) \\ \Delta E_{\mathrm{dev}} & \text { Electrode potential deviation; also referred to as the electrode potential (V) } \\ E_{1,0} & \text { Potential difference between the cathode and anode (V) } \\ E_{2,0} & \text { Standard reduction potential of the } \mathrm{R} / \mathrm{R}^{n-} \text { redox couple (V) }\end{array}$




\begin{tabular}{|c|c|}
\hline$F$ & Faraday constant $\left(96485 \mathrm{C} \mathrm{mol}^{-1}\right)$ \\
\hline $\mathrm{H}_{\mathrm{CO}_{2}}$ & Henry's law constant for $\mathrm{CO}_{2}\left(\mathrm{M} \mathrm{bar}^{-1}\right)$ \\
\hline$\widetilde{H}_{\mathrm{CO}_{2}}$ & Relative $\mathrm{CO}_{2}$ solubility \\
\hline$K_{1}$ & Binding coefficient of $\mathrm{R}^{n-}$ relative to dissolved $\mathrm{CO}_{2}$ \\
\hline$K_{2}$ & Binding coefficient of $\mathrm{R}$ relative to dissolved $\mathrm{CO}_{2}$ \\
\hline$K_{\mathrm{g}, 1}$ & Binding coefficient of $\mathrm{R}^{n-}$ relative to gaseous $\mathrm{CO}_{2}$ \\
\hline$K_{\mathrm{g}, 2}$ & Binding coefficient of $\mathrm{R}$ relative to gaseous $\mathrm{CO}_{2}$ \\
\hline$n$ & Number of electrons transferred per capture molecule \\
\hline$P$ & Pressure (bar) \\
\hline$P_{0}$ & Standard pressure (1 bar) \\
\hline$P_{\mathrm{CO}_{2}}$ & Partial pressure of $\mathrm{CO}_{2}$ (bar) \\
\hline$P_{\mathrm{CO}_{2}, \mathrm{feed}}$ & Partial pressure of $\mathrm{CO}_{2}$ in the feed gas stream (bar) \\
\hline$P_{\mathrm{CO}_{2}, \text { raf }}$ & Partial pressure of $\mathrm{CO}_{2}$ in the raffinate stream (bar) \\
\hline$\tilde{P}_{\mathrm{CO}_{2}}$ & Dimensionless partial pressure of $\mathrm{CO}_{2}$ \\
\hline$\widetilde{P}_{\mathrm{CO}_{2}, \text { feed }}$ & Dimensionless partial pressure of $\mathrm{CO}_{2}$ in the feed gas stream \\
\hline$\tilde{P}_{\mathrm{CO}_{2}, \text { raf }}$ & Dimensionless partial pressure of $\mathrm{CO}_{2}$ in the raffinate stream \\
\hline$q$ & Number of $\mathrm{CO}_{2}$ molecules bound per capture molecule \\
\hline$\left[\mathrm{R}_{0}\right]$ & Total capture species concentration \\
\hline [R] & Concentration of $\mathrm{R}(\mathrm{M})$ \\
\hline$\left[\mathrm{R}^{n-}\right]$ & Concentration of $\mathrm{R}^{n-}(\mathrm{M})$ \\
\hline$\left[\mathrm{R}\left(\mathrm{CO}_{2}\right)_{q}\right]$ & Concentration of $\mathrm{R}\left(\mathrm{CO}_{2}\right)_{q}(\mathrm{M})$ \\
\hline$\left[\mathrm{R}\left(\mathrm{CO}_{2}\right)_{q}^{n-}\right]$ & Concentration of $\mathrm{R}\left(\mathrm{CO}_{2}\right)_{q}^{n-}(\mathrm{M})$ \\
\hline$[\widetilde{\mathrm{R}}]$ & Dimensionless concentration of $\mathrm{R}$ \\
\hline$\left[\widetilde{\mathrm{R}}^{n-}\right]$ & Dimensionless concentration of $\mathrm{R}^{n-}$ \\
\hline$\left[\widetilde{\mathrm{R}}\left(\mathrm{CO}_{2}\right)_{q}\right]$ & Dimensionless concentration of $\mathrm{R}\left(\mathrm{CO}_{2}\right)_{q}$ \\
\hline
\end{tabular}




$\begin{array}{ll}{\left[\widetilde{\mathrm{R}}\left(\mathrm{CO}_{2}\right)_{q}^{n-}\right]} & \text { Dimensionless concentration of } \mathrm{R}^{\left(\mathrm{CO}_{2}\right)_{q}^{n-}} \\ R_{\mathrm{u}} & \text { Universal gas constant }\left(8.314 \mathrm{~J} \mathrm{~mol}^{-1} \mathrm{~K}^{-1}\right) \\ T & \text { Absolute temperature }(\mathrm{K}) \\ W & \text { Work }\left(\mathrm{J} \text { mol } \mathrm{CO}_{2}^{-1}\right) \\ W_{\text {min }} & \text { Minimum work for separation }\left(\mathrm{J} \mathrm{mol} \mathrm{CO}_{2}^{-1}\right) \\ x_{\mathrm{a}} & \text { State of charge } \\ \Delta x_{\mathrm{a}} & \text { State of charge swing } \\ x_{\mathrm{CO}_{2}} & \begin{array}{l}\text { Normalized total } \mathrm{CO}_{2} \text { concentration in the electrolyte (including physically } \\ \left.\text { dissolved } \mathrm{CO}_{2} \text { and } \mathrm{CO}_{2} \text { bound to the capture species }\right)\end{array} \\ \Delta x_{\mathrm{CO}_{2}} & \text { Normalized quantity of separated } \mathrm{CO}_{2}\end{array}$

Greek symbols

$\begin{array}{ll}\alpha & \mathrm{CO}_{2} \text { capture fraction } \\ \eta_{\text {thermodynamic }} & \text { Thermodynamic efficiency } \\ \eta_{\text {faradaic }} & \text { Faradaic efficiency } \\ \eta_{\text {combined }} & \text { Combined efficiency }\end{array}$

\section{REFERENCES}

(1) International Energy Agency. Net Zero by 2050, https://www.iea.org/reports/net-zero-by2050, (accessed 2021-08-05).

(2) IPCC, 2018: Summary for Policymakers. Global Warming of $1.5^{\circ} \mathrm{C}$. An IPCC Special Report on the impacts of global warming of $1.5^{\circ} \mathrm{C}$ above pre-industrial levels and related global greenhouse gas emission pathways. [Masson-Delmotte, V., Zhai, P., Pörtner, H.-O., Roberts, D., Skea, J., Shukla, P. R., Pirani, A., Moufouma-Okia, W., Péan, C., Pidcock, R., Connors, S., Matthews, J. B. R., Chen, Y., Zhou, X., Gomis, M. I., Lonnoy, E., Maycock, T., Tignor, M., Waterfield, T., Eds. (eds.)]., https://www.ipcc.ch/sr15/chapter/spm/, (accessed 2021-08-17).

(3) Leung, D. Y. C.; Caramanna, G.; Maroto-Valer, M. M. An Overview of Current Status of Carbon Dioxide Capture and Storage Technologies. Renew. Sustain. Energy Rev. 2014, 39, 426-443. DOI: 10.1016/j.rser.2014.07.093.

(4) Wang, X.; Song, C. Carbon Capture From Flue Gas and the Atmosphere: A Perspective. Front. Energy Res. 2020, 8 (560849). DOI: 10.3389/fenrg.2020.560849. 
(5) Minx, J. C.; Lamb, W. F.; Callaghan, M. W.; Fuss, S.; Hilaire, J.; Creutzig, F.; Amann, T.; Beringer, T.; De Oliveira Garcia, W.; Hartmann, J.; Khanna, T.; Lenzi, D.; Luderer, G.; Nemet, G. F.; Rogelj, J.; Smith, P.; Vicente Vicente, J. L.; Wilcox, J.; Del Mar Zamora Dominguez, M. Negative Emissions - Part 1: Research Landscape and Synthesis. Environmental Research Letters. June 1, 2018, p 063001. DOI: 10.1088/1748-9326/aabf9b.

(6) Socolow, R.; Desmond, M.; Aines, R.; Blackstock, J.; Bolland, O.; Kaarsberg, T.; Lewis, N.; Mazzotti, M.; Pfeffer, A.; Sawyer, K.; Siirola, J.; Smit, B.; Wilcox, J. Direct Air Capture of CO2 with Chemicals: A Technology Assessment for the APS Panel on Public Affairs. Am. Phys. Soc. 2011.

(7) Lackner, K. S. The Thermodynamics of Direct Air Capture of Carbon Dioxide. Energy 2013, 50 (1), 38-46. DOI: 10.1016/j.energy.2012.09.012.

(8) Fasihi, M.; Efimova, O.; Breyer, C. Techno-Economic Assessment of CO2 Direct Air Capture Plants. J. Clean. Prod. 2019, 224, 957-980. DOI: 10.1016/j.jclepro.2019.03.086.

(9) CO2 Capture Plant https://www.mhi.com/products/engineering/co2plants.html (accessed $2021-09-13)$.

(10) Shell CANSOLV® $\mathrm{CO}_{2}$ Capture System https:/www.shell.com/businesscustomers/catalysts-technologies/licensed-technologies/emissions-standards/tail-gastreatment-unit/cansolv-co2.html (accessed 2021 -09-13).

(11) Fluor Econamine FG Plus - Carbon Capture Technology https://www.fluor.com/aboutfluor/corporate-information/technologies/fluor-econamine-fg-plus (accessed 2021 -02 -13).

(12) Climeworks offers a technology to reverse climate change. https://climeworks.com/ (accessed $2020-11-23$ ).

(13) Global Thermostat https://globalthermostat.com/ (accessed 2020 -11 -23).

(14) Carbon Engineering https://carbonengineering.com/ (accessed $2021-02-13$ ).

(15) Brogioli, D.; La Mantia, F.; Yip, N. Y. Thermodynamic Analysis and Energy Efficiency of Thermal Desalination Processes. Desalination 2018, 428, 29-39. DOI: 10.1016/J.DESAL.2017.11.010.

(16) Agrawal, R.; Herron, D. M. Optimal Thermodynamic Feed Conditions for Distillation of Ideal Binary Mixtures. AIChE J. 1997, 43 (11), 2984-2996. DOI: 10.1002/aic.690431111.

(17) Lively, R. P.; Realff, M. J. On Thermodynamic Separation Efficiency: Adsorption Processes. AIChE J 2016, 62 (10), 3699-3705. DOI: 10.1002/aic.15269.

(18) Svendsen, H. F.; Hessen, E. T.; Mejdell, T. Carbon Dioxide Capture by Absorption, Challenges and Possibilities. Chem. Eng. J. 2011, 171 (3), 718-724. DOI: 10.1016/j.cej.2011.01.014.

(19) Zhao, B.; Liu, F.; Cui, Z.; Liu, C.; Yue, H.; Tang, S.; Liu, Y.; Lu, H.; Liang, B. Enhancing the Energetic Efficiency of MDEA/PZ-Based CO2 Capture Technology for a $650 \mathrm{MW}$ Power Plant: Process Improvement. Appl. Energy 2017, 185, 362-375. DOI: 10.1016/J.APENERGY.2016.11.009.

(20) Le Moullec, Y.; Kanniche, M. Screening of Flowsheet Modifications for an Efficient Monoethanolamine (MEA) Based Post-Combustion CO2 Capture. Int. J. Greenh. Gas 
Control 2011, 5 (4), 727-740. DOI: 10.1016/J.IJGGC.2011.03.004.

(21) Heldebrant, D.; Jiang, Y.; Zheng, R.; Barpaga, D.; Freeman, C.; Koech, P. K.; Malhotra, D.; Whyatt, G.; Zwoster, A. Performance and Cost Predictions of 2-EEMPA, and Future Opportunities for Water-Lean Post-Combustion Capture Solvents. Proc. 15th Greenh. Gas Control Technol. Conf. 15-18 March 2021 2021. DOI: 10.2139/SSRN.3813876.

(22) Karimi, M.; Hillestad, M.; Svendsen, H. F. Capital Costs and Energy Considerations of Different Alternative Stripper Configurations for Post Combustion CO2 Capture. Chem. Eng. Res. Des. 2011, 89 (8), 1229-1236. DOI: 10.1016/J.CHERD.2011.03.005.

(23) Zoannou, K. S.; Sapsford, D. J.; Griffiths, A. J. Thermal Degradation of Monoethanolamine and Its Effect on CO2 Capture Capacity. Int. J. Greenh. Gas Control 2013, 17, 423-430. DOI: 10.1016/j.ijggc.2013.05.026.

(24) Sanz-Pérez, E. S.; Murdock, C. R.; Didas, S. A.; Jones, C. W. Direct Capture of CO2 from Ambient Air. Chemical Reviews. October 12, 2016, pp 11840-11876. DOI: 10.1021/acs.chemrev.6b00173.

(25) Prentice, G. Electrochemical Engineering. Encycl. Phys. Sci. Technol. 2003, 143-159. DOI: 10.1016/B0-12-227410-5/00205-2.

(26) Laudadio, G.; de Smet, W.; Struik, L.; Cao, Y.; Noël, T. Design and Application of a Modular and Scalable Electrochemical Flow Microreactor. J. Flow Chem. 2018, 8 (3-4), 157-165. DOI: 10.1007/s41981-018-0024-3.

(27) Yuan, Y.; Aiwen, L. Is Electrosynthesis Always Green and Advantageous Compared to Traditional Methods? Nat. Commun. 2020, 11 (802). DOI: 10.1038/s41467-020-14322-z.

(28) Stern, M. C.; Simeon, F.; Herzog, H.; Alan Hatton, T. An Electrochemically-Mediated Gas Separation Process for Carbon Abatement. In Energy Procedia; 2013; Vol. 37, pp 11721179. DOI: 10.1016/j.egypro.2013.05.214.

(29) Stern, M. C.; Simeon, F.; Herzog, H.; Hatton, T. A. Post-Combustion Carbon Dioxide Capture Using Electrochemically Mediated Amine Regeneration. Energy Environ. Sci. 2013, 6, 2505-2517. DOI: 10.1039/c3ee41165f.

(30) Wang, M.; Hariharan, S.; Shaw, R. A.; Hatton, T. A. Energetics of Electrochemically Mediated Amine Regeneration Process for Flue Gas CO2 Capture. Int. J. Greenh. Gas Control 2019, 82, 48-58. DOI: 10.1016/j.ijggc.2018.12.028.

(31) Watkins, J. D.; Siefert, N. S.; Zhou, X.; Myers, C. R.; Kitchin, J. R.; Hopkinson, D. P.; Nulwala, H. B. Redox-Mediated Separation of Carbon Dioxide from Flue Gas. Energy and Fuels 2015, 29 (11), 7508-7515. DOI: 10.1021/acs.energyfuels.5b01807.

(32) Rahimi, M.; Catalini, G.; Puccini, M.; Hatton, T. A. Bench-Scale Demonstration of CO2 Capture with an Electrochemically Driven Proton Concentration Process. RSC Adv. 2020, 10 (29), 16832-16843. DOI: 10.1039/d0ra02450c.

(33) Rahimi, M.; Catalini, G.; Hariharan, S.; Wang, M.; Puccini, M.; Hatton, T. A. Carbon Dioxide Capture Using an Electrochemically Driven Proton Concentration Process. Cell Reports Phys. Sci. 2020, 1 (4), 100033. DOI: 10.1016/j.xcrp.2020.100033.

(34) Jin, S.; Wu, M.; Gordon, R. G.; Aziz, M. J.; Kwabi, D. G. PH Swing Cycle for CO2 Capture 
Electrochemically Driven through Proton-Coupled Electron Transfer . Energy Environ. Sci. 2020, 13 (10), 3706-3722. DOI: 10.1039/d0ee01834a.

(35) Huang, C.; Liu, C.; Wu, K.; Yue, H.; Tang, S.; Lu, H.; Liang, B. CO2 Capture from Flue Gas Using an Electrochemically Reversible Hydroquinone/Quinone Solution. Energy Fuels 2019, 33, 3380-3389. DOI: 10.1021/acs.energyfuels.8b04419.

(36) Xie, H.; Jiang, W.; Liu, T.; Chen, B.; Liang, B.; Xie, H.; Jiang, W.; Liu, T.; Wu, Y.; Wang, Y.; Chen, B.; Niu, D. Low-Energy Electrochemical Carbon Dioxide Capture Based on a Biological Redox Proton Low-Energy Electrochemical Carbon Dioxide Capture Based on a Biological Redox Proton Carrier. Cell Reports Phys. Sci. 2020, 1 (5), 100046. DOI: 10.1016/j.xcrp.2020.100046.

(37) Xie, H.; Wu, Y.; Liu, T.; Wang, F.; Chen, B.; Liang, B. Low-Energy-Consumption Electrochemical CO2 Capture Driven by Biomimetic Phenazine Derivatives Redox Medium. Appl. Energy 2020, 259. DOI: 10.1016/j.apenergy.2019.114119.

(38) DuBois, D. L.; Miedaner, A.; Bell, W.; Smart, J. C. Electrochemical and Electrocatalytic Reactions of Carbon Dioxide; Sullivan, B. P., Krist, K., Guard, H. E., Eds.; 1993.

(39) Mizen, M. B.; Wrighton, M. S. Reductive Addition of CO2 to 9,10-Phenanthrenequinone. J. Electrochem. Soc. 1989, 136 (4), 941-946.

(40) Nagaoka, T.; Nishii, N.; Fujii, K.; Ogura, K. Mechanisms of Reductive Addition of CO2 to Quinones in Acetonitrile. J. Electroanal. Chem. 1992, 322 (1-2), 383-389. DOI: 10.1016/0022-0728(92)80090-Q.

(41) Scovazzo, P.; Poshusta, J.; Dubois, D.; Koval, C.; Noble, R. Electrochemical Separation and Concentration of $<1 \%$ Carbon Dioxide from Nitrogen. J. Electrochem. Soc. 2003, 150 (5), D91-D98. DOI: 10.1149/1.1566962.

(42) Gurkan, B.; Simeon, F.; Hatton, T. A. Quinone Reduction in Ionic Liquids for Electrochemical CO2 Separation. ACS Sustain. Chem. Eng. 2015, 3, 1394-1405. DOI: 10.1021/acssuschemeng.5b00116.

(43) Ishida, H.; Ohba, T.; Yamaguchi, T.; Ohkubo, K. Interaction between $\mathrm{CO} 2$ and Electrochemically Reduced Species of N-Propyl-4,4'-Bipyridinium Cation. Chem. Lett. 1994, 905-908. DOI: 10.1246/cl.1994.905.

(44) Ranjan, R.; Olson, J.; Singh, P.; Lorance, E. D.; Buttry, D. A.; Gould, I. R. Reversible Electrochemical Trapping of Carbon Dioxide Using 4,4'-Bipyridine That Does Not Require Thermal Activation. J. Phys. Chem. Lett. 2015, 6, 4943-4946. DOI: 10.1021/acs.jpclett.5b02220.

(45) Singh, P.; Rheinhardt, J. H.; Olson, J. Z.; Tarakeshwar, P.; Mujica, V.; Buttry, D. A. Electrochemical Capture and Release of Carbon Dioxide Using a Disulfide-thiocarbonate Redox Cycle. J. Am. Chem. Soc. 2017, 139, 1033-1036. DOI: 10.1021/jacs.6b10806.

(46) Schmidt, M. H.; Miskelly, G. M.; Lewis, N. S. Effects of Redox Potential, Steric Configuration, Solvent, and Alkali Metal Cations on the Binding of Carbon Dioxide to Cobalt(I) and Nickel(I) Macrocycles.

(47) Appel, A. M.; Newell, R.; Dubois, D. L.; Dubois, M. R. Concentration of Carbon Dioxide by Electrochemically Modulated Complexation with a Binuclear Copper Complex. Inorg. 
Chem. 2005, 44 (9), 3046-3056. DOI: 10.1021/ic050023k.

(48) Voskian, S.; Hatton, T. A. Faradaic Electro-Swing Reactive Adsorption for CO2 Capture. Energy Environ. Sci 2019, 12, 3530. DOI: 10.1039/c9ee02412c.

(49) Liu, Y.; Ye, H. Z.; Diederichsen, K. M.; Van Voorhis, T.; Hatton, T. A. Electrochemically Mediated Carbon Dioxide Separation with Quinone Chemistry in Salt-Concentrated Aqueous Media. Nat. Commun. 2020, 11 (1), 2278. DOI: 10.1038/s41467-020-16150-7.

(50) Tam, S. M.; Tessensohn, M. E.; Tan, J. Y.; Subrata, A.; Webster, R. D. Competition between Reversible Capture of $\mathrm{CO} 2$ and Release of $\mathrm{CO} 2 \bullet-$ Using Electrochemically Reduced Quinones in Acetonitrile Solutions. J. Phys. Chem. C 2021, 125-11916. DOI: 10.1021/acs.jpcc.1c00997.

(51) Brushett, F. R.; Aziz, M. J.; Rodby, K. E. On Lifetime and Cost of Redox-Active Organics for Aqueous Flow Batteries. ACS Energy Lett. 2020, 5 (3), 879-884. DOI: 10.1021/ACSENERGYLETT.0C00140.

(52) Shaw, R. A.; Hatton, T. A. Electrochemical CO2 Capture Thermodynamics. Int. J. Greenh. Gas Control 2020, 95. DOI: 10.1016/j.ijggc.2019.102878.

(53) Bell, W. L.; Miedaner, A.; Smart, J. C.; DuBois, D. L.; Verostko, C. E. Synthesis and Evaluation of Electroactive CO2 Carriers. SAE Transactions. 1988, pp 544-552. DOI: $10.2307 / 44470355$.

(54) Wang, M.; Lawal, A.; Stephenson, P.; Sidders, J.; Ramshaw, C. Post-Combustion CO2 Capture with Chemical Absorption: A State-of-the-Art Review. Chem. Eng. Res. Des. 2011, 89 (9), 1609-1624. DOI: 10.1016/J.CHERD.2010.11.005.

(55) Sanpasertparnich, T.; Idem, R.; Bolea, I.; deMontigny, D.; Tontiwachwuthikul, P. Integration of Post-Combustion Capture and Storage into a Pulverized Coal-Fired Power Plant. Int. J. Greenh. Gas Control 2010, 4 (3), 499-510. DOI: 10.1016/J.JJGGC.2009.12.005.

(56) Hasan, M. M. F.; Baliban, R. C.; Elia, J. A.; Floudas, C. A. Modeling, Simulation, and Optimization of Postcombustion CO2 Capture for Variable Feed Concentration and Flow Rate. 2. Pressure Swing Adsorption and Vacuum Swing Adsorption Processes. Ind. Eng. Chem. Res. 2012, 51 (48), 15665-15682. DOI: 10.1021/IE301572N.

(57) Newell, R.; Appel, A.; Dubois, D. L.; Dubois, M. R. Studies of Bicarbonate Binding by Dinuclear and Mononuclear Ni(II) Complexes. Inorg. Chem. 2005, 44 (2), 365-373. DOI: 10.1021/ic049202c.

(58) Peover, M. E.; White, B. S. The Formation of the Superoxide Ion by Electrolysis of Oxygen in Aprotic Solvents. Chem. Commun. 1965, 10 (10), 183-184. DOI: 10.1039/C19650000183.

(59) Satopää, V.; Albrecht, J.; Irwin, D.; Raghavan, B. Finding a "Kneedle" in a Haystack: Detecting Knee Points in System Behavior. Proc. - Int. Conf. Distrib. Comput. Syst. 2011, 166-171. DOI: 10.1109/ICDCSW.2011.20. 